\title{
Educational potential of teaching evolution as an interdisciplinary science
}

\author{
Susan Hanisch ${ }^{1,2,3,4^{*}}$ (i) and Dustin Eirdosh ${ }^{1,3,4}$
}

\begin{abstract}
Evolution education continues to struggle with a range of persistent challenges spanning aspects of conceptual understanding, acceptance, and perceived relevance of evolutionary theory by students in general education. This article argues that a gene-centered conceptualization of evolution may inherently limit the degree to which these challenges can be effectively addressed, and may even precisely contribute to and exacerbate these challenges. Against that background, we also argue that a trait-centered, generalized, and interdisciplinary conceptualization of evolution may hold significant learning potential for advancing progress in addressing some of these persistent challenges facing evolution education. We outline a number of testable hypotheses about the educational value of teaching evolutionary theory from this more generalized and interdisciplinary conception.
\end{abstract}

Keywords: Conceptual understanding, Transfer of learning, Misconception, Gene-centrism, Systems thinking, Human evolution, Cultural evolution

\section{Introduction}

Evolutionary theory is continuously advancing and developing. New theoretical considerations based on new methods and empirical findings are being added over the years and decades into a more nuanced understanding of how evolution operates across the biological world and beyond.

Since Darwin's time, and especially in recent decades, scholars beyond traditionally biological fields have used concepts from evolutionary theory to explain observable variation and change of characteristics in populationsfrom economics, archeology, anthropology, sustainability science, linguistics, history, psychology, and computer science, to name just a few (see discussion in Hanisch and Eirdosh 2020a). While the history of extending evolution into the human domain is rife with scientific and ethical questions, many of these modern interdisciplinary developments in turn, have significantly helped to advance

\footnotetext{
*Correspondence: susan.hanisch@eva.mpg.de

${ }^{1}$ Department of Comparative Cultural Psychology, Max Planck Institute for Evolutionary Anthropology, Leipzig, Germany

Full list of author information is available at the end of the article
}

conceptual understanding of evolutionary theory, for example through the development of evolutionary game theory and agent-based modelling methods (Gintis 2009; McElreath and Boyd 2007; Rice 2004).

What all of these developments indicate is that evolution has become conceptualized more broadly as a theory of change that helps understand the variation and distribution of heritable traits of various kinds, rather than being restricted to rather gene-focused conceptualizations stemming from the so-called Modern Synthesis (MS).

What do these developments mean for how we teach evolution science, in biology, but also in other subject areas? Might these developments provide opportunities for advancing the understanding, acceptance or relevance of evolution, or might they in fact pose greater challenges for conceptual clarity in the future? Must these developments be actively incorporated to "keep up" with current science, or can these developments be safely put aside for various reasons?

These big picture questions frame the focus of our project, Teaching evolution as an interdisciplinary science, with the aim to encourage in the evolution education

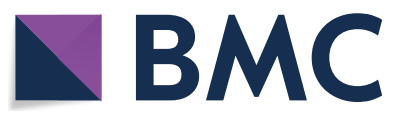

(C) The Author(s) 2020. This article is licensed under a Creative Commons Attribution 4.0 International License, which permits use, sharing, adaptation, distribution and reproduction in any medium or format, as long as you give appropriate credit to the original author(s) and the source, provide a link to the Creative Commons licence, and indicate if changes were made. The images or other third party material in this article are included in the article's Creative Commons licence, unless indicated otherwise in a credit line to the material. If material is not included in the article's Creative Commons licence and your intended use is not permitted by statutory regulation or exceeds the permitted use, you will need to obtain permission directly from the copyright holder. To view a copy of this licence, visit http://creativeco mmons.org/licenses/by/4.0/. The Creative Commons Public Domain Dedication waiver (http://creativecommons.org/publicdomain/ zero/1.0/) applies to the data made available in this article, unless otherwise stated in a credit line to the data. 
community (and other education communities) a wider discussion of these issues and propose a research program that explicitly explores these areas of educational potential.

In this article, we provide some perspectives and considerations in order to advance this aim, not least because, in our own educational initiatives, we have begun to actively incorporate aspects of evolutionary science from these broader and interdisciplinary perspectives. Importantly, our motivation to consider these broader conceptualizations of evolution for education is not merely driven by a concern for teaching current scientific discourse and nature of science. We argue that an understanding of evolution as it emerges from these interdisciplinary developments may help overcome some of the enduring learning difficulties in evolution education, and may provide more opportunities for interdisciplinary connections, both across biological subdisciplines as well as across the social sciences and humanities more broadly.

A general clarification of current evolutionary science is beyond the scope of this article. In Hanisch and Eirdosh (2020a), we provide such an overview of current evolutionary science discourse and a conceptual clarification of core concepts in evolutionary theory that highlights the generalization of concepts beyond genefocused conceptualizations and beyond the domain of biology, as well as the broadening of evolutionary and developmental dynamics as more complex than commonly taught. We hypothesize that these generalizations of evolutionary concepts-while challenging the currently dominating gene-centered approaches to evolution education and assessment-may hold significant educational potential.

In Hanisch and Eirdosh (2020b), we discuss examples from evolution education discourse and materials that highlight how gene-focused conceptualizations prevail in standards, materials, and assessment tools, which may lead to inconsistencies, problematic representations of concepts, and problematic assessment items.

This article is structured as follows. In the following section, we summarize the persistent challenges of evolution understanding and acceptance that continue to prevail in evolution education. We then highlight areas of progress that have been made in terms of alleviating these challenges, as well as knowledge gaps and emerging opportunities for furthering this progress by employing an interdisciplinary, trait-centered conceptualization ofevolutionary theory. In the remainder of the article, we address each area of challenge in more detail, first regarding persistent barriers to evolution understanding, and then regarding persistent barriers to evolution acceptance, and provide hypotheses for how a generalized conception of evolutionary theory might help in further alleviating each area of challenge. In the concluding section, we point out existing and emerging teaching approaches designed to test our hypotheses, which we plan to explore in our design-based research project Teaching evolution as an interdisciplinary science.

\section{Persistent challenges in evolution education}

The evolution education community continues to be confronted with persistent challenges to evolution understanding and acceptance. One area of challenges pertains to the difficulty of understanding evolutionary concepts and principles due to conflicts with students' intuitive conceptions as well as the prevalence of common misconceptions and cognitive biases (Gregroy 2009; Pobiner 2016; Rosengren et al. 2012; Sinatra et al. 2008). Intuitive conceptions thought to hinder evolution understanding include the notion that individuals can adapt, that traits can be acquired during the lifetime and then transmitted to offspring and that natural selection is an event rather than a distributed process (Gregory 2009). Cognitive biases include essentialist views of organisms or groups of organisms such that variation between and within organisms that is important for natural selection is overlooked (e.g. Gelman 2003; Shtulman and Schulz 2008), teleological notions of causality that invoke a purpose, need, function, or goal (e.g. Barnes et al. 2017; Kelemen 2012), and similar intentionalist notions of causality that invoke an intentional agent (Gregory 2009; Varella 2018). Furthermore, due to some of these misconceptions and biases, the distributed, deep-time, multi-causal, multilevel nature of evolution and its emergent outcomes is difficult for students to understand (Chi et al. 2012; Cooper 2016; Jacobson 2001; Petrosino et al. 2015; Xu and Chi 2016).

Another area of challenge has to do with evolution acceptance due to emotional and motivational hurdles. One of those hurdles appears to be based on the perceived negative implications of evolutionary theory to personal life and society (e.g. Brem et al. 2003). For example, the notions of competition, extinction, and violence in nature might provoke in students a form of "existential anxiety" (Legare et al. 2018). Furthermore, a significant challenge is presented by the fact that evolutionary explanations of life, including the origins of humans, can conflict with religious beliefs and other factors of personal identity (e.g. Barnes et al. 2017; Bertka et al. 2019).

Note that there are complex interactions between challenges of understanding and acceptance, since emotional factors often cannot be separated from conceptual learning, and learning is understood by many scholars to involve affective and motivational aspects (Pugh 2011; Sinatra 2005). This is why evolution education has been 
particularly concerned with the apparent problem that understanding of evolution does not appear to coincide with acceptance, or motivation, or perceived relevance of evolution to students (Dunk et al. 2019; Pobiner 2016).

For example, Brem et al. (2003) investigated the perceived personal and social consequences of evolutionary theory among US undergraduate students in five potential areas of impact. Among other things, students $(n=135)$ were asked to rate to what degree they found evolutionary theory makes it harder or easier to justify selfishness or racial and ethnic discrimination, or whether evolutionary theory increases a sense of puropse and self-determination. Overwhelmingly, students held quite negative attitudes towards evolution regarding these notions. Furthermore, knowledge about evolution did not differ significantly between students across nine identified belief groups (from strong creationist to nontheistic evolutionist), and the extent of negative perceptions was strikingly similar across these belief groups. Authors conclude: "While we would hope that knowing more about evolution would lead to a richer understanding of complicated issues, these results suggest that the more a person knows about evolution, the more negative they become." (Brem et al. 2003, 194).

In the following section, we summarize some existing approaches and the progress that has been made to date towards addressing these persistent challenges. We then highlight knowledge gaps and emerging findings regarding the educational potential of an interdisciplinary evolutionary theory.

In the remainder of the article, we address each of these areas of difficulty and highlight how emerging interdisciplinary conceptions and applications of evolutionary theory might help make further progress on alleviating these challenges to effective evolution education.

\section{Previous approaches and progress in resolving persistent challenges}

While the challenges mentioned above continue to persist, it is important to emphasize that progress has also been made in the development of instructional strategies for addressing these.

For example, it has been shown that the mechanism of natural selection can be successfully taught to children as young as 5 years old through storybooks and activities (Brown et al. 2020; Emmons et al. 2016; Emmons et al. 2018; Kelemen et al. 2014; Shtulman et al. 2016). Brown et al. (2020) showed that while 7-9 year old students had predominant teleological explanations of the origins of traits, these could be significantly reduced by a short intervention in classroom settings. Importantly, in this context achieving an understanding of natural selection does not require an understanding of genetic variation and genetic inheritance (which presumably would be too abstract for young children). In contrast, other authors have argued that to increase understanding of evolution, teachers should "teach genetics prior to teaching evolution" (Mead et al. 2017).

Bruckermann et al. (2020) reviewed research into young children's understanding of important concepts of evolutionary theory, namely variation, inheritance, and natural selection, and effective interventions to use these conceptions as stepping stones, or conversely, to overcome them in order to develop a scientific understanding of evolution. Authors highlight that there might be complex interactions between children's intuitive understandings and biases that can hinder or foster understanding of natural selection. For example, educators might build on children's teleological notion that organisms respond to needs, as it can help them appreciate trait variation between organisms, or educators might build on children's early developing understanding of inheritance and essentialist biases to introduce rudimentary concepts of genetic inheritance.

Harms and Reiss (2019) summarize the successful teaching strategies for achieving student understanding and for addressing student attitudes towards evolutionary theory based on the chapters of their edited book. Pedagogical approaches that have been found to be effective in science education more broadly, have also been found to promote understanding and acceptance of evolution, including inquiry-based learning, use of models, games, and simulations, and using metacognitive strategies for students to explore their own conceptual change and understanding.

Several authors also found or proposed that the use of human examples, or examples that are closer to student everyday experience, can increase motivation and the perceived relevance of evolution (e.g. Pobiner et al. 2018; Nettle 2010), in turn affecting conceptual understanding.

Pugh et al. (2010) and Heddy and Sinatra (2013) built on the notion of transformative experience and its role in fostering conceptual change in their interventions with high school and undergraduate students. In these studies, instructional strategies that model or encourage the active use of concepts in everyday experience have been found to foster conceptual understanding and positive emotional affect in relation toevolution.

Deniz and Borgerding (2018) present the state of evolution education around the globe, including the degree of evolution acceptance across a range of countries. Evolution acceptance across countries ranges widely from about $80 \%$ in New Zealand, to about $60 \%-70 \%$ in countries like the UK and German-speaking countries, 50\% in countries like US, Greece, and Ecuador, and 17\% in Malaysia. Religion thus continues to present one of the 
most significant hurdles to the widespread teaching of evolutionary principles to the general public. To overcome this hurdle in the US context, Bertka et al. (2019) developed a teaching resource that was designed to help teachers and students to integrate religious beliefs with science in a more flexible and open fashion, in part by acknowledging and emphasizing that religious belief and science can coexist and be integrated. The interventions were rated positively by teachers and students across a range of religiosity.

Plutzer et al. (2020) found that between 2007 and 2019 the amount of time devoted to the teaching of human evolution and of evolutionary processes in the US has increased from an average of 4.1 to $7.7 \mathrm{~h}$ and 9.8 to $12.4 \mathrm{~h}$, respectively. The percentage of teachers who convey evolutionary theory as established scientific fact also increased, and the percentage of teachers that consider evolution as a unifying theme in the biology classroom remained high and increased slightly to almost $70 \%$. Identified factors that appear to be responsible for these improvements in the teaching of evolution are the adoption of the Next Generation Science Standards in the US as well as improvements in teacher and professional development.

\section{Advancing progress by teaching evolution as a pluralistic and interdisciplinary science}

Despite progress, there still exist significant knowledge gaps that might point to untapped potential for the evolution education world. Ziadie and Andrews (2018) conducted a review of research in evolution education to identify gaps in collective pedagogical content knowledge across themes in evolutionary theory. The authors found that, compared to the wealth of publications dealing with student thinking, assessment, and instructional strategies around the mechanism of natural selection, there are knowledge gaps regarding evolution of behavior and evolutionary developmental biology (no studies for high school level), coevolution, and sexual selection, particularly a lack of assessment tools for these concepts. Legare et al. (2018) point out that "[c]urrent methods for assessing students' understanding of evolution are grounded in the evolution of non-human animals and non-mentalistic traits. (...) social scientists may well need their own assessment tools-tools capable of gauging students' understanding of the evolved nature of human cognition and human behavior." (p. 34). In this article, we argue that including more strongly the evolved nature of human cognition and behavior in evolution education may provide opportunities for tapping into student everyday experience and to increase students' perceived relevance of evolution, however, as Legare et al. (2018) note, this may require new approaches to assessing (and even defining) evolution understanding.

Nonetheless, some notable efforts exist to integrate a range of more complex notions and interdisciplinary examples of evolutionary change into high school and undergraduate evolution education. Thompson (2010) notes that the concept of coevolution should be more strongly emphasised in biology education. Thanukos (2010) highlights the educational potential provided by examples of coevolution in terms of student interest, the fact that examples of coevolution "can be used to illustrate key aspects of natural selection that students frequently miss" (p. 71), and the ability to integrate evolution concepts in the topic of ecology (thereby addressing the problem that evolution is still often covered as a separate topic in the curriculum, rather than as a theory that underlies and informs all other topics in biology, Nehm et al. 2009).

Love (2013) argued for an approach to evolution education that integrates the role of developmental processes and ecological interactions. Hiatt et al. (2013) surveyed US high school and university student conceptions of the developmental aspects of evolution (evo-devo), and found that students had difficulty integrating development and evolution. This may similarly stem from the aforementioned lack of integration of evolution with other topics in the high school biology curriculum (Nehm et al. 2009). Jamieson and Radick (2017) adapted a genetics course to tackle the issue of genetic determinism presumably stemming from an emphasis on Mendelian genetics, by putting a stronger emphasis on complex causes of phenotypes. Apodaca et al. (2019) included concepts like nongenetic inheritance, phenotypic plasticity, and niche construction in their concept map of evolutionary theory for biology education. However, as we note above, there is currently a lack of knowledge on student thinking and preconceptions, instructional strategies, and assessment tools available for teachers to explore these concepts in the classroom, particularly at the high school level (Ziadie and Andrews, 2018).

Araújo (2020) emphasizes the diversity and complexity in current evolutionary theory that should be embraced in order to more strongly establish the centrality of evolutionary theory in biology education, and criticizes the preponderance of gene-focused notions of evolution in education: "[E] evolution at both basic and higher education levels is strongly based on the original evolutionary synthesis [i.e. Modern Synthesis], with a focus on population genetics, and this is one of the reasons for the failure in establishing the centrality of evolution in biology teaching. Given the diversity and complexity of contemporary evolution theory, a more pluralistic perspective to evolutionary teaching 
is required. I propose that a causally pluralistic evolutionary worldview, which expands the range of causal factors contributing to evolutionary change, is essential when it comes to establishing the centrality of evolution in biology teaching." Araújo $(2020,1)$.

Wilson et al. (2019) explore and document the role of evolutionary theory in informing higher education curricula across a range of disciplines and topics. O'Brien et al. (2009), O'Brien and Gallup (2011), O'Brien and Wilson (2010), and Wilson (2005) present an interdisciplinary undergraduate evolution course ("Evolution for Everyone") that expands beyond the biological domain into the human sciences, includes topics such as cultural evolution, and applies evolutionary concepts to areas such economics and politics. As the authors lament, "evolution is still taught primarily as a subject in the biological sciences, rather than a theory that can help to unify the human-related disciplines." (O'Brien et al. 2009, 445), and "[ $t]$ here appear to be two walls of resistance, one denying the theory [of evolution] altogether and the other denying its relevance to human affairs." (Wilson 2005, 1001). O'Brien et al. (2009) found in a pre-post study that the course increased understanding and acceptance of evolution as well as perceived relevance to human-related disciplines and to everyday life. Wilson (2005) found a pronounced increase in student views about the relevance of evolution to human behavior, across religious and political background, as well as across a wide range of prior exposure to evolution. It would be interesting to know to what degree these outcomes of their course compare to more biology and gene-focused evolution courses, however, as Wilson (2005) notes, it is difficult to establish what an appropriate control would be.

Pugh et al. (2014) highlighted how the concept of natural selection is applied to various domains outside biology, such as economics, psychology, cognition and learning, and investigated high school students' ability to equally transfer the concept from biological examples to culture. The authors call for instructional approaches that make transfer an explicit goal and that help students to develop flexible representations of the concept of natural selection across domains. However, we are not aware of instructional strategies and their assessment for high school level that explicitly target this transfer of evolutionary concepts beyond the domain of biology.

In this article, we build on these emerging calls and approaches in evolution education towards a more generalized, interdisciplinary treatment of evolutionary theory across grade levels in general education. We propose thatthis approach has the potential to furtheradvance progress towards addressing the persistent challenges of evolution understanding and acceptance. To our knowledge, there is a dearth of empirical research or assessment tools to investigate this potential (see also the review by Ziadie \& Andrews, 2018).

In fact, we argue that the teaching of evolution through a gene-centered conception might also inherently contribute to and exacerbate the persistent challenges in evolution education, thus constraining progress in addressing some of the challenges.

As we highlight further below, one set of reasons is that many intuitive understandings, such as the notion that individuals can adapt or that culture evolves, are considered misconceptions, or at best outside of the domain, under a gene-focused conceptualization of evolution. By contrast, under a more trait-centered, interdisciplinary conceptualization of evolution (see Hanisch and Eirdosh, 2020a), such notions might rather be considered scientifically adequate and integrated parts of explaining complex developmental and evolutionary dynamics. This might in turn serve as a stepping stone towards extending these concepts to the domain of genetic evolution.

Another set of reasons relates to the fact that a gene-centered conception of evolution limits the available examples of evolved and evolving phenomena that can be discussed in the classroom, thereby limiting the opportunities for far transfer and for fostering motivation and perceived relevance.

A gene-centered conception of evolution also tends to de-emphasize the complex, reciprocal and multilevel nature of causality in development and evolution, thereby limiting the degree to which evolution education can foster systems thinking.

Finally, a gene-centered conception of evolution may de-emphasize the active role of organisms in shaping evolutionary trajectories, thereby limiting the degree to which students' knowledge and experience of goal-directed behaviors can become an integrated part of evolutionary explanations (see Hanisch and Eirdosh 2020c).

These elements of a gene-focused conceptualization of evolution and contrasting framing within a trait-centered conceptualization (Fig. 1) are sometimes, but not always, antithetical to each other. More often than not, adopting a trait-centered approach requires only a nuanced difference in emphasis or enrichment of gene-centered approaches.

Figure 2 as well as Tables 1 and 3 provide an overview of our hypotheses regarding the potential to further advance progress in evolution education, which we expand upon in more detail in the following sections.

\section{Addressing challenges of evolution understanding}

Table 1 summarizes some of the persistent challenges in evolution education related to evolution understanding. We hypothesize that these challenges may be in part overcome in the following ways: 


\section{Elements of a gene-centered evolution education}

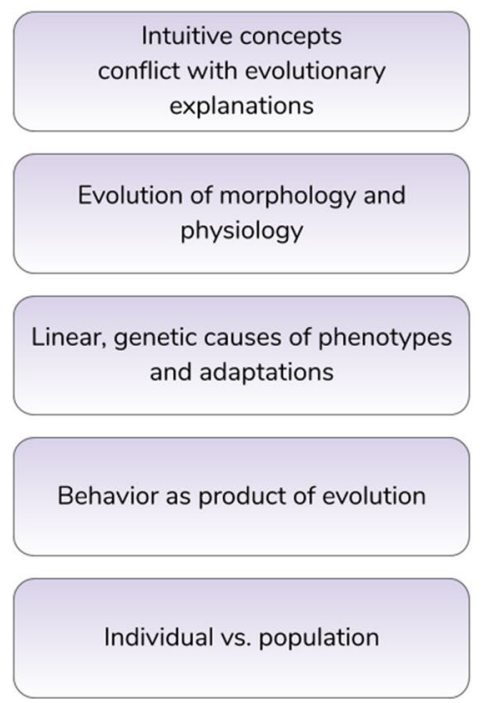

Requires an increased emphasis on...

\section{Elements of a trait-centered evolution education}

Intuitive concepts can be part of evolutionary explanations

Evolution of (human) behavior, cognition, culture

Complex causes of phenotypes and adaptations

Behavior as selection pressure

\section{Self as population}

Fig. 1 Elements of a gene-centered evolution education compared with contrasting elements of a trait-centered approach

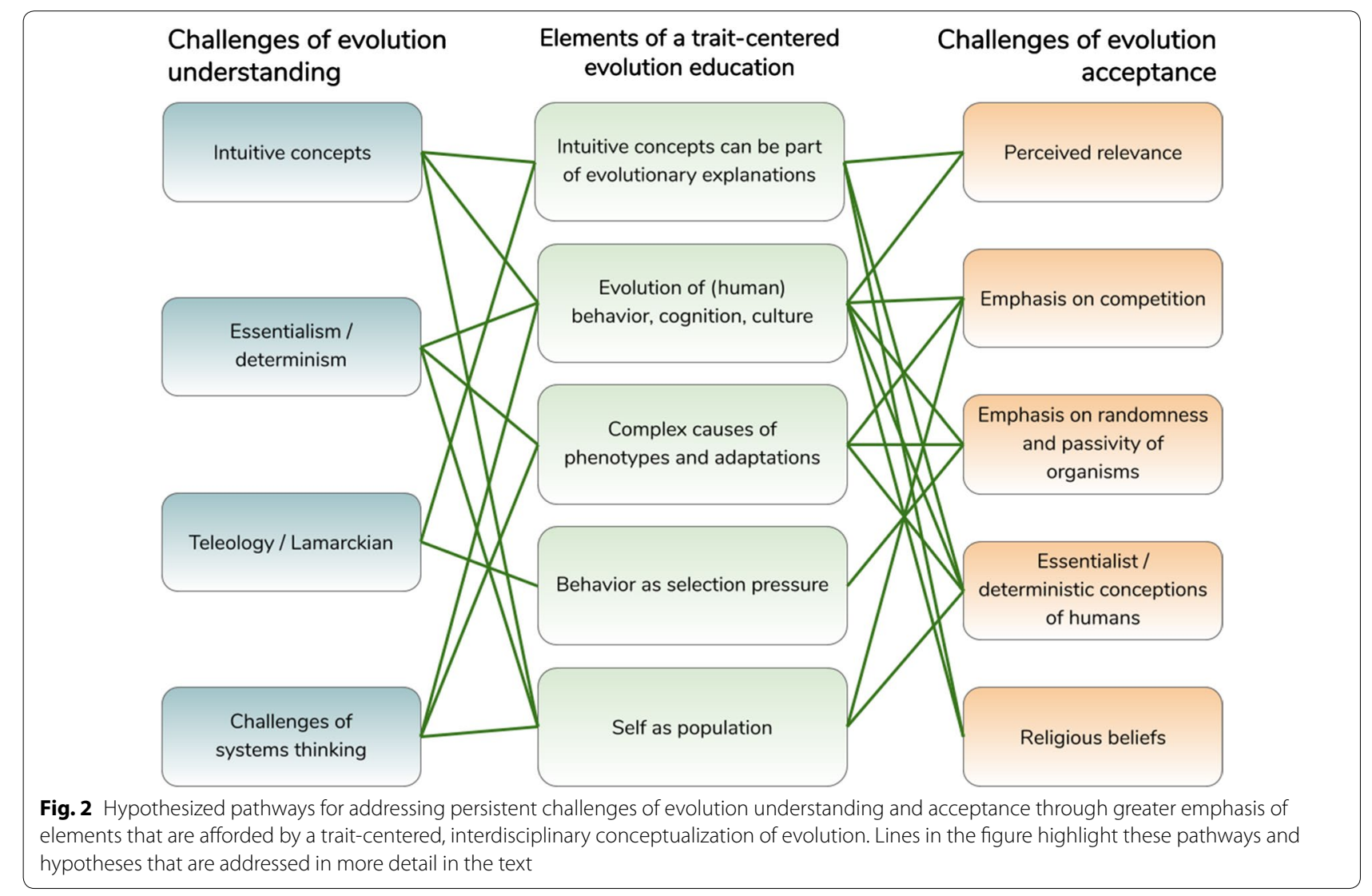




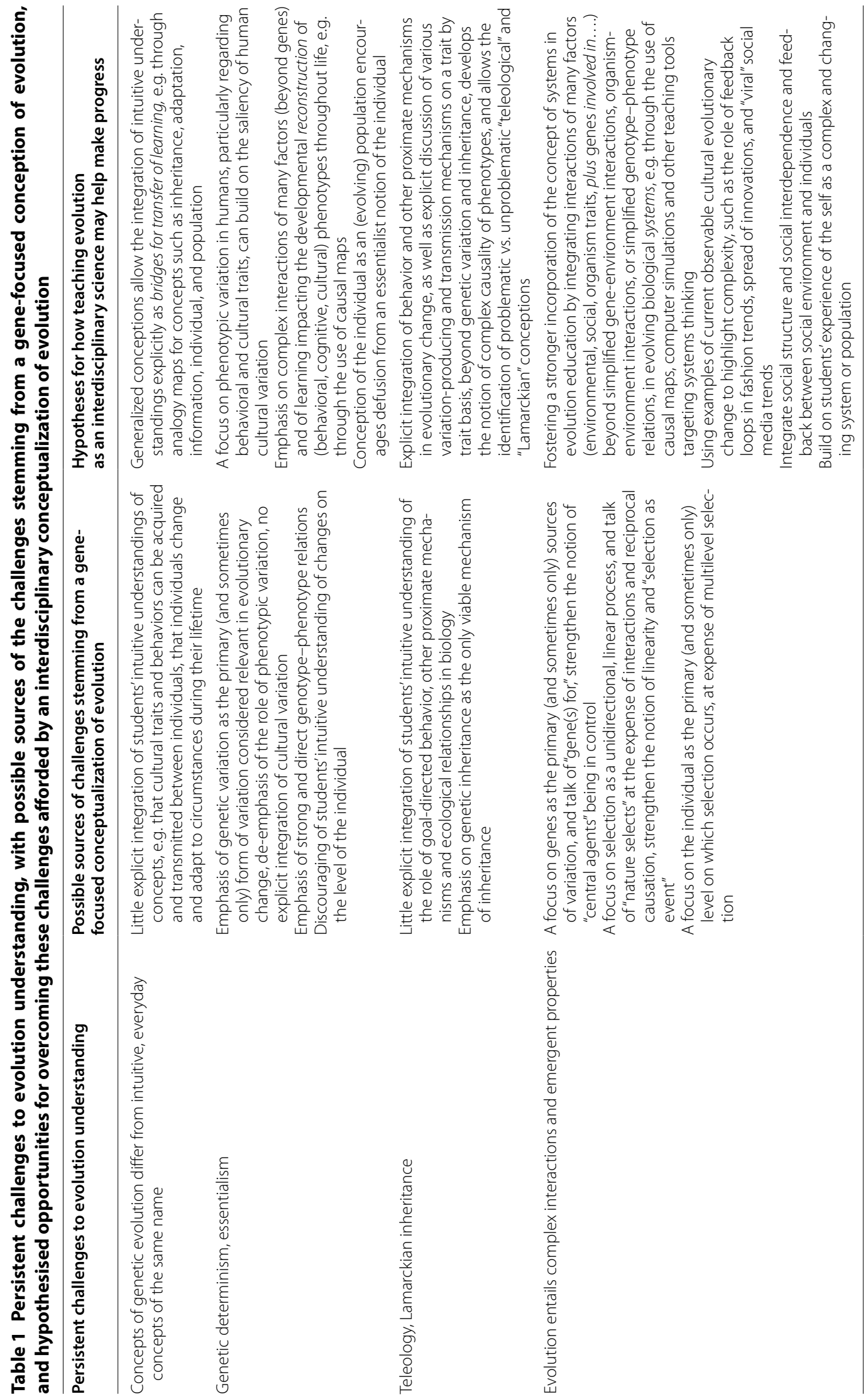


- Addressing misconceptions due to intuitive concepts by encouraging explicit transfer of learning from intuitive or observable phenomena to novel or more abstract phenomena, and explicit integration of intuitive understandings under a general conceptualization of evolution

- Addressing essentialism and genetic determinism by emphasising phenotypic variation and complex developmental reconstruction of phenotypes, including cultural phenotypes, as well as the notion of self as population or complex system

- Addressing teleological reasoning and Lamarckian inheritance by encouraging the explicit integration of behaviors as shaping selection pressure in evolutionary change, as well as student understanding of various mechanisms of inheritance into explanations of evolutionary change

- Addressing challenges related to complexity and systems thinking by emphasising complex causality in explanations of evolutionary and developmental change, exploring observable cultural evolutionary dynamics, and enhancing the notion of self as population or complex system.

\section{Addressing misconceptions due to intuitive concepts through transfer of learning}

Humans have an elaborated capacity for social cognition, inuitively noticing and interpreting the behavioral variation that pervades their everyday lives (Hermann et al. 2007; Heyes 2018). Evolution education has long recognized that students' intuitive concepts may pose challenges to scientifically adequate understanding of evolution science (see Shtulman 2017). Here we hypothesize that a trait-centered, generalized, and interdisciplinary conceptualization of evolution could help address this persistent challenge through fostering increased transfer of learning across relevant knowledge domains towards deeper conceptual understanding (sensu Stern et al. 2017).

Foundational to education science is the idea that all learning requires the transfer of prior learning to novel or more abstract phenomena (Kirschner and Hendrick 2020; Aubusson et al. 2006; Gentner et al. 2001; Haskell 2000). The role of analogical relations between prior concepts and novel experience in learning has led some cognitive scientists to argue that analogy is the "core of cognition" (Hofstadter 2001, 499). Despite the centrality of analogical transfer of learning to education, there remains a diversity of views as to how educators should practically engage this insight.

Kinchin (2000) contrasts a "systems view" of conceptual change with a "misconceptions" view. According to the misconceptions view, students' existing ideas "interfere with learning expert concepts" and teaching "must help pupils replace their misconceptions", whereas according to the systems view, "Pupils' prior conceptions provide the only starting point for instruction" and "Teaching should help the student to appropriately extend their prior knowledge." (Kinchin 2000, 180, emphasis original). Similarly in evolution education, it has been recognized that intuitive student conceptions may provide bridges, rather than barriers, which would allow students to transfer their understanding towards a more complex conceptual understanding (Evans and Rosengren 2018).

Opfer et al. (2012) also present considerations for designing evolution understanding assessment tools based on the cognitive foundations of learning and understanding, such as the role of core concepts that allow experts to organize and retrieve large stores of information, the role of causal relationships in expert explanations of phenomena, and the tendency of experts to increasingly generalize and abstract concepts and principles such that they can apply them across a range of different phenomena and even domains (i.e. far transfer, Barnett and Ceci 2002).

Pedagogical approaches for developing increasingly generalized and abstract representations of concepts that promote transfer of learning include the use of analogies and case comparisons (Alfieri et al. 2013) and the construction of analogy maps, whereby source and target phenomena can be compared by underlying common principles, processes, and other "deep" characteristics, thus developing the skill to transfer understanding to novel phenomena that may, on the surface, appear very different or involve different substrates and contextspecific mechanisms (Gentner et al. 2004; Glynn 2008; Harrison and Treagust 2006). Goldstone and Wilensky (2003) provide evidence about the potential of computer simulations of various concreteness and abstraction to promote increasing generalization and transfer of principles of complex adaptive systems. Evolution educators have pointed out the need to assess student understanding of evolutionary concepts across a range of context examples, such as covering familiar and unfamiliar traits as well as a range of taxa (Nehm et al. 2010, 2012; Opfer et al.2 012). Emmons et al. (2018) investigated 6 and8 year old children's ability to transfer the concept of natural selection between scenarios involving similar traits (which they classify as near transfer) and dissimilar traits (which they classify as far transfer) and after a 1 month delay with the help of story books and guided classroom discussions. Kindergartners were able to transfer to similar scenarios but had trouble transferring to a more dissimilar context, while 8 year olds were able to transfer near and far to the same degree. 
Barnett and Ceci (2002) highlight how definitions of near and far transfer vary widely across studies, and propose a taxonomy of far transfer. According to Barnett and Ceci (2002), transfer can be considered near or far along several dimensions: the similarity in knowledge domain (e.g. biology vs. economics), modality (e.g. text vs. images), and physical, temporal, functional and social context.

For example, according to the classification by Barnett and Ceci (2002), exploring and fostering students' ability to apply the logic of natural selection to different traits or species would be an instance of near transfer because it is in the same knowledge domain of biology, but might be considered far transfer if the context is presented in a different modality (e.g. text and pictures) or presented weeks or years later, or if it is set in a different context than the classroom or academic setting. As such, the different aspects of transfer studied by Emmons et al. (2018) highlighted above, while able to detect an important shift between 6 - and 8-year olds' ability to transfer to increasingly dissimilar contexts and after a 1 month time lag, may all still be considered near transfer on a number of dimensions, particularly the domain (all examples are animals) and the physical and functional context (all testing was done in the school and was an academic activity). Assessment tools for natural selection for secondary and undergraduate students, while often using a range of context examples, similarly do not seem to capitalize on maximizing far transfer in the dimensions of domain (examples are within the domain of biology, and often more restricted still, involve animal morphological and physiological traits) and functional contexts (academic vs. applied to everyday life) (e.g. Anderson et al. 2002; Kalinowski et al. 2016; Nehm et al. 2012).

We argue that a trait-centered interdisciplinary evolutionary theory can further advance evolution understanding based on the role of far transfer in conceptual understanding.
On the one hand, transfer of evolutionary concepts and methods has been foundational to the application of evolutionary theory to other domains beyond biology (e.g. Lake and Venti 2009; Levinson and Gray 2012; MacCallum et al. 2012; Prentiss et al. 2011; Sweller and Sweller 2006). For example, cultural evolution science studies the changes of cultural variation in populations (of humans but also other animals) over time, using concepts and methods that have originally beendeveloped within evolutionary biology, such as modelling of population dynamics and phylogenetic analysis as well as comparative behavioral observations and experiments (Cultural Evolution Science 2020; Mesoudi, 2011). In this regard, variations of analogy maps and similar conceptual clarifications have been put forward by evolutionary scientists that compare processes and principles across different formulations or domains of evolutionary theory (e.g. Mesoudi 2011; Laland et al. 2015; Sweller and Sweller 2006). We draw on these in our conceptual clarification of evolution as an interdisciplinary science (Hanish and Eirdosh 2020a) as well as Table 2.

Thus, the application of evolutionary theory to the domain of culture arguably represents an opportunity to develop in students an even deeper and more abstract conceptual understanding of concepts of variation, inheritance/transmission, and selection (as well as other evolutionary processes such as drift) as can be achieved by focusing on biological examples alone. In order to investigate this potential, Pugh et al. (2014) explored 9th and 10th grade high school students' ability to transfer the concept of natural selection to the domain of culture by asking "Not only do organisms change over time, but so do [TV programmes/shoes]. In what ways, if any, is this change similar to evolution of organisms through natural selection? In what ways, if any, is it different?" (p. 26). Students' ability to correctly transfer the concept of natural selection to TV shows and shoes was rather small-26\% showed no transfer at all, and more than half of students

Table 2 Analogy table comparing genetic evolution and cultural evolution as well as individual-level learning by general evolutionary concepts of variation, selection, and inheritance of traits. For an extended table and references, see Hanisch and Eirdosh (2020a, Table 1)

\begin{tabular}{|c|c|c|c|}
\hline Concept, process, principle & Genetic evolution & Cultural evolution & Learning \\
\hline How is variation of traits caused? & Mutation, recombination & $\begin{array}{l}\text { Creativity, innovations, recombina- } \\
\text { tion of ideas, mistakes, reactions } \\
\text { to new environments }\end{array}$ & $\begin{array}{l}\text { Creativity, innovations, social learning, } \\
\text { recombination of ideas, mistakes, } \\
\text { reactions to new environments }\end{array}$ \\
\hline How does selection of traits occur? & $\begin{array}{l}\text { Higher chances of survival and } \\
\text { reproduction compared to other } \\
\text { trait variants }\end{array}$ & $\begin{array}{l}\text { Higher chances of survival and } \\
\text { reproduction (natural selection); } \\
\text { higher appeal or attractiveness of } \\
\text { the trait (cultural selection) }\end{array}$ & Success in achieving a goal \\
\hline $\begin{array}{l}\text { How are traits inherited, transmit- } \\
\text { ted, or retained? }\end{array}$ & $\begin{array}{l}\text { Biological reproduction, mitosis/ } \\
\text { meiosis }\end{array}$ & $\begin{array}{l}\text { Social learning/imitation, teaching; } \\
\text { technologies and infrastructure } \\
\text { that endure }\end{array}$ & $\begin{array}{l}\text { Reinforcement, encoding of neural } \\
\text { connections in the brain }\end{array}$ \\
\hline
\end{tabular}


only provided answers coded as surface level transfer such as using phrases like "TV shows adapt" without further explication, while $28 \%$ showed some deep structure transfer that described the process of natural selection, using concepts like variation and survival of the fittest. These numbers dropped further at a 5-week follow up test. Importantly, students that showed higher levels of deep structure transfer also tended to show higher levels of conceptual understanding of natural selection, whereas there was no correlation between conceptual understanding and surface-level transfer. However, in this study, students were not explicitly instructed about the goal of transfer, or about the exact way that natural selection can be transferred across domains. This may be one reason that the relation between student conceptual understanding and ability for deep transfer was still rather small. Nonetheless, it seems promising that more than a quarter of students were able to transfer their understanding of biological natural selection to the domain of culture on a deeper level at all. Authors conclude that "We propose that for students to successfully transfer the concept of natural selection, they need to develop a particular set of cognitive structures related to the concept. Such cognitive structures include, but are not limited to, multiple representations of the concept (...), connections between the concept and multiple contexts and purposes (...), and conditional knowledge about how, when, where and how to apply the concept." (p. 31). Instructional strategies suggested by Pugh et al. (2014) include the exploration of various components of natural selection across multiple cases within and outside of biology, use of analogies, and explicit framing of the purpose of learning as transferring and applying a concept generatively to novel contexts.

Towards this aim, Table 2 provides an example analogy map we have used to engage pre-service educators from multiple subject areas in identifying and discussing the surficial difference and deeper structural similarities between genetic and cultural evolution in populations, as well as learning in individuals, along the three overarching concepts of variation, selection and inheritance/ transmission/retention that are involved in the process of natural selection (see Additional file 1 for a lesson plan on exploring cultural evolution further). Note that the transfer of evolutionary processes to learning at the level of the individual represents an opportunity to link to and appropriately expand students' notion that individuals can adapt (see further below).

Another educational opportunity to promote conceptual understanding of evolution through far transfer may be due to the fact that concepts such as variation, inheritance, and selection as they are understood within cultural evolution science (see Hanisch and Eirdosh 2020a;
Table 2), could often be considered closer to students' everyday experience and thus intuitive notions of these concepts, compared to the exclusively gene-centered understandings.

For example, regarding the ability to notice variation, Shtulman and Schulz (2008) found that more children and adults regarded behavioral traits as potentially and actually variable among individuals of a species compared to external or internal anatomical traits.

Regarding intuitive notions of inheritance, studies have shown that human folk biological and folk sociological intuitions across cultures also appear to be in line with the conceptualization of trait transmission through multiple possible mechanisms. Moya et al. (2015) assessed causal reasoning across cultures (US, Fiji, Peru) and ages (childhood to $>70$ years) about transmission of different kinds of traits, namely morphological traits vs. cultural traits such as beliefs and skills, through "switched at birth" vignettes. Results showed that, while younger children tended to be biased towards thinking that all traits are inherited from biological parents, by middle childhood, subjects across cultures tended to reason that morphological traits are more likely to be inherited from biological parents before birth, and that beliefs (a type of cultural trait) are more likely to be inherited through social transmission from others in the social environment. Authors attribute this ability to differentiate between mechanisms of transmission to a mix of folk biology and folk sociology in humans across cultures. Similar studies equally indicate that "young children have a theory of kinship that allows them to differentiate biological inheritance and cultural transmission" (Duncan et al. 2009, 664; Venville et al. 2005).

In this view, it could be hypothesized that engaging students in understanding the variability, transmission mechanisms, and context-specific functional consequences of behavioral or cultural traits couldrepresent an important "stepping stone" (sensu Evans and Rosengren 2018) towards understanding gene-centered concepts in biology, which are known to be difficult for students to grasp (Duncan et al. 2009).

Further still, student ideas of behavioral and cultural change might in fact be considered part of a scientifically adequate evolutionary account, particularly regarding cultural and gene-culture coevolutionary dynamics and the role of behavior-led adaptation and niche construction (e.g. Henrich 2016; Laland et al. 2011; Odling-Smee et al. 2003; Richerson and Boyd 2005). Opportunities for far transfer to different physical and functional contexts outside the classroom thus present themselves because students experience a wide range of cultural evolutionary phenomena in their everyday lives, which has implications for student motivation and perceived relevance 
of evolution (see below). As Prentiss et al. (2011) point out in their presentation of the evolution of skateboard designs by employing evolutionary concepts and methods, "our familiarity with changes in modern material culture provide an excellent opportunity for teachers to utilize material culture evolution to inform larger discussions of evolution in general". This view is in contrast to how some evolution education scholars appear to make a hard distinction between evolution as applied to culture and evolution as used in the domain of biology (e.g. van Dijk and Reydon, 2010; see Hanisch and Eirdosh $2020 \mathrm{~b}$ for a discussion), rather than integrating them into a higher level causal model of evolutionary change. In fact, cultural evolution is already part of the biology education curriculum in Germany, and in Hanisch and Eirdosh (2020b) we document how some German biology textbooks (as well as primary school education materials, Graf and Schmidt-Salomon 2017), make explicit the analogical nature between genetic and cultural evolution, but in our view, do not provide sufficient guidance to students and teachers to think more carefully about the structural similarities and differences between biological and cultural evolution.

Stepping from more intuitive to less intuitive understandings requires carefully structured scaffolding towards generalized understanding of core concepts that can be flexibly and appropriately transferred into specific contexts (Stern et al. 2017; Vendetti et al. 2015). Thus, from the "conceptual ecologies" (Kinchin 2000) and teaching for conceptual understanding perspectives (Stern et al. 2017), in order to help students to develop a deeper, transferable understanding of concepts like, for example, "inheritance", we can encourage them to reflect a little deeper on, enrich and complexify their current existing understanding of this concept by prompting them with specific reflection questions such as: How would you define it? What characterizes it? What are some examples of things that can be inherited or passed on between organisms? Through what ways or processes can things be inherited or passed on to others? Who can inherit what from whom and to whom? With some prompting, students' existing "conceptual ecologies" related to inheritance can be elaborated to a broad understanding that organisms inherit, pass on or transmit various things and characteristics to other organisms through various mechanisms. With the explicit construction of analogy maps, the concept of inheritance can serve as an overarching causal process involved in evolutionary change, and genetic inheritance can become one particular kind of inheritance, whereby the differences between other kinds of inheritance are compared in terms of the specific details of certain aspects and mechanisms, such as the kinds of things that are inherited (e.g. genes vs. behaviors vs. technologies vs. money), how they are inherited (e.g. biological reproduction vs. imitation vs. persistence vs. by social norms and laws), or to whom in a group they can be inherited (e.g. vertically between parents and offspring, or horizontally and obliquely).

Similar approaches for building on students' existing, but often unreflected and rudimentary, knowledge of everyday terms are thinkable for almost all the concepts that are central to evolutionary theory (see Hanisch and Eirdosh 2020a), including "adaptation", "natural selection" (see Pugh et al. 2014) and the term "evolution" itself. Such potential for transfer may also help foster connections across topics in the biology curriculum, as well as interdisciplinary connections across school subjects, and may have implications regarding motivational hurdles, e.g. by promoting relevance of evolution to student lives.

\section{Addressing essentialism and genetic determinism}

Essentialism is a cognitive bias whereby students tend to not see the variation among individuals of a population or species, often ascribing to them a certain unchangeable essence (Gelman 2003; Pobiner 2016). Such essentialist biases stand in the way of a conceptual understanding of evolution by natural selection, which requires population thinking and an appreciation of the role of variation (Shtulman 2006).

Genetic determinism is a cognitive bias or misconception whereby students tend to expect that phenotypes are solely and directly determined by genes and not at all or barely influenced by other factors (Jamieson and Radick 2017).

We argue that an emphasis on genetic variation as the primary (and sometimes only) form of variation that is relevant in evolutionary change and in the development of phenotypes may reinforce essentialism and genetic determinism by de-emphasizing the role of phenotypic variation.

Standards and textbooks tend to emphasize simple and direct genotype-phenotype relations, sometimes using genotype and phenotype seemingly interchangeably (e.g. University of California Museum of Paleontology, 2009; see Hanisch and Eirdosh 2020b for more examples and discussion). This may reinforce genetic determinism by de-emphasizing the role of developmental reconstruction (sensu Oyama et al. 2001; see Hanisch and Eirdosh 2020a, c) of phenotypes, whereby phenotypes develop by the integration of a variety of heritable resources and factors, including but not limited to genes. Oyama et al. (2001) argue that conceptions of evolution and development that only regard genetic information as determining phenotype and as relevant in shaping evolutionary trajectories are merely an extension of earlier preformationist notions that held that organisms are in some way preformed in 
the embryo, rather than more appropriate epigenetic notions that consider development as a process of complex causality involving many sources of information. Similarly, an emphasis on a direct genotype-phenotype relation in the classroom can be regarded as problematic, since the notion of an immutable "essence" of organisms that is considered part of essentialist biases is simply replaced (and possibly even reinforced) by the concept of genes. Indeed, Ergazaki et al. (2015) introduced the concept of "species-genes" and "body-trait-genes" to provide 5-year old children with a rudimentary biological explanation of the mechanism that explains species and trait-resemblance between parents and offspring. The intervention increased children's understanding of biological inheritance and decreased their endorsement for the causal role of parents' wishes and intentions in influencing their offsprings' species and body traits. However, the danger might be that an "essence-like idea of genes" (Eragazi et al. 2015, 3136) reinforces essentialist notions of an immutable essence of species and individuals. As Bruckermann et al. (2020) highlight, there may be complex interactions and trade-offs between building on children's intuitive notions of teleology and essentialism towards an understanding of evolution.

Genetic determinism may also be further reinforced if educators regard as deterministic the notion that one gene determines one trait, seaking to overcome such notions with an emphasis that many genes are involved in a phenotype, or that it is the proteins produced in the expression of these genes that lead to phenotypes (e.g. Duncan et al. 2009). Hanisch and Eirdosh (2020b) document examples of problematic educational materials potentially reinforcing, explicitly or implicitly, notions of genetic determinism.

In contrast, Jamieson and Radick (2017) adapted an undergraduate genetics course to tackle the issue of genetic determinism presumably stemming from an emphasis onMendelian genetics. They sought to emphasize the role of developmental factors such as behaviors and environment in the emergence of a focal phenotype by the use of causal maps, and to deemphasize language like "gene for", replacing it with "gene(s) involved in". The authors pointed out that the "simple-to-complex trajectory, for all its abundant virtues, runs the risk of creating students who cling to the simple (...). Instead (...) our students were introduced to the complexity of genetic influences in the first lecture." (Jamieson and Radick 2017, 1268). We argue that the approach of "leading with complexity" (Fuentes 2020), can also be applied to evolution education and may help overcome a range of challenges of evolution understanding, as well as emotional and motivational hurdles (see below). Figure 3 visualizes the different notions of phenotype causation characteristic of a gene-centered and trait-focused understanding of evolution.

It has been argued that teaching about evolutionary concepts like variation through human examples can have positive impacts on student understanding, because variation in our species appears to be more salient to students (Nettle 2010). However, within a gene-focused conceptualization of evolution, the particularly striking behavioral and cultural variation in our species can not be integrated as relevant or appropriate forms of variation for gene-centered evolutionary explanations. Under the generalized notion of evolution within cultural evolution science, however, cultural phenotypes can become valid phenomena whose change and distribution can be investigated through the mechanisms of variation, selection and transmission (as well as other processes; see the previous section, Table 2, Additional file 1, and Hanisch and Eirdosh, 2020a). Further still, such cultural variation can act as selection pressures driving evolutionary change at the genetic level, as is the case in the expanding set of documented instances of culture driven geneculture co-evolution, such as the evolution of lactose tolerance and other adaptations to agricultural practices, behavioral adaptations to socio-cultural environments, immunity to pathogens, the evolution of language, and the concept of self-domestication (e.g. Chudek and Henrich 2011; Hare et al. 2012; Jablonka et al. 2012; Laland et al. 2010). While the social and constructed environment, combined with social learning, shape behavioral traits across a wide range of animals (Hoppitt and Laland 2013; Odling-Smee et al. 2003; Whiten and van Schaik 2007), these dynamics are especially pronounced in our own species, where the socio-cultural environment has a prominent role in influencing our behavior and cognition throughout development.

Similarly, under a gene-focused conceptualization of evolution, students' intuitive understanding that individuals change and adapt throughout life in interaction with their environment is usually discouraged, being framed as an inaccurate use of the term adaptation (i.e. individuals don't adapt, only populations do). This may reinforce essentialist and deterministic notions. Instead, under a generalized conceptualization of evolution, the concept of the individual can be explicitly transferred to the concept of an (evolving) population, changing through the mechanisms of variation and selective retention in the case of learning and behavioral change (see Table 2; Hanisch and Eirdosh 2020a). As Shtulman (2006) highlights "science educators should be aware that their students are likely to analogize the adaptation of species to the adaptation of individuals, (...). One strategy for ridding students of such essence-based analogies would be to contrast them with population-based analogies" ( $\mathrm{p}$. 


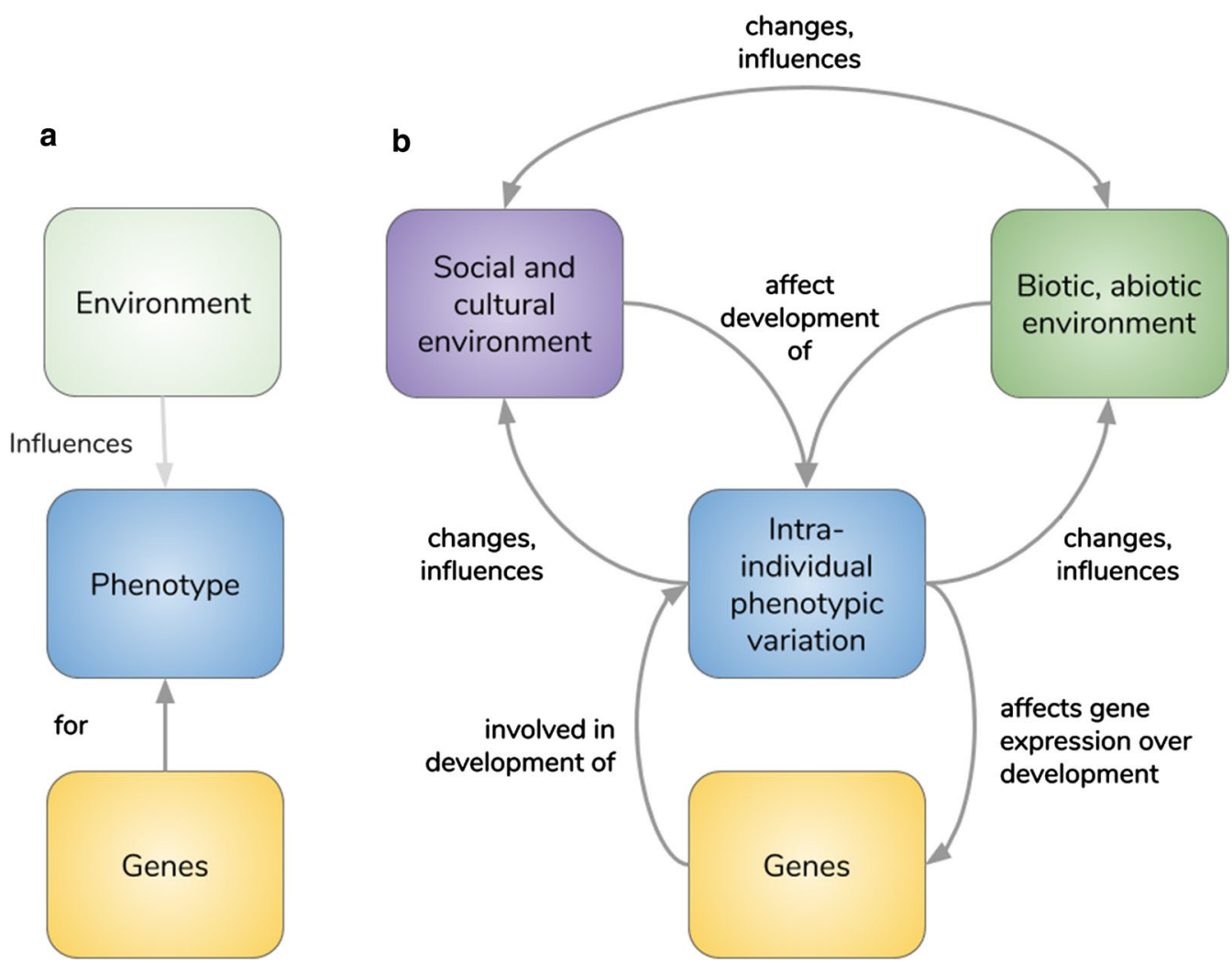

Fig. 3 Different representations of the causes of phenotypes. a Emphasis on linear and direct genotype-phenotype relations, sometimes with a footnote about the role of environment, that characterizes gene-focused notions about the causes of phenotypes. b Multi-causal and reciprocal interactions shaping intra individual phenotypic variation throughout development, as conceptualized in trait-centered and generalised evolution science. Note that in this case, various inheritance streams, beyond genetic inheritance, can become relevant in the reconstruction of phenotypes, and hence in the evolution of adaptations. Sources: Laland et al. (2011); Oyama et al. (2001); Jamieson and Radick (2017)

186). Thus, the question is whether population-based analogies could appropriately be applied to the level of individuals, which could then be conceptualized to adapt and evolve by population-level evolutionary processes. In fact, this is what scientists across a range of disciplines have done, including in cancer research, psychology, and cognition, as well as in evolutionary biology towards explaining the evolution of multicellularity (e.g. Aktipis 2016; Greaves 2018; Hayes and Sanford 2015; Rosenbaum, 2014; Smith and Szathmáry 1995). Thus, evolutionary processes are being recognized among many scientists to operate across multiple scales of time and levels of organization, allowing for an enrichment rather than correction of students' intuitive conceptions of individual-level adaptive change. However, as we highlighted above, this requires careful scaffolding and instructional design to help students transfer appropriately between the processes involved in the adaptation on the level of individuals and adaptation on the level of populations of individuals (see Table 2). Indeed, we recognize that many in the evolution education community remain reluctant to accept the conceptualization of individual organisms as evolving populations of cells and traits, however, at the level of evolutionary science this concept has a long history, remaining significant in current discourse. In light of the educational aim of teaching for conceptual clarity, we argue this learning potential should be on the research agenda for evolution education.

\section{Addressing challenges of teleological reasoning and Lamarckian inheritance}

Challenges of evolution understanding also revolve around a class of misconceptions that have been termed teleological thinking, and a similar class of misconceptions that have been termed "Lamarckian" thinking.

Teleology is defined in different ways by educators, but often it is described as involving a reference to purpose, need or function in causal explanations of phenomena (e.g. Brown et al. 2020; Kelemen 2012). At the same time, students' reference to need has also been considered to be an appropriate bridge or scaffolding towards an understanding of natural selection because of the recognition 
of the role of trait function (Evans and Rosengren 2018; Legare et al. 2013). Similarly, it has been pointed out that student thinking about causality in biology may not be an invalid "teleological" notion but a valid account of proximate and ecological interactions, or an implicit understanding about the role of antecedent causes in bringing about functional traits (e.g. Gouvea and Simon 2018; Ojalehto et al. 2013; see Hanisch and Eirdosh 2020c, for an extended discussion).

Similar problems apply to Lamarckian thinking, where it has been pointed out that educators also define Lamarckian conceptions differently, and different student conceptions may be falsely categorized as "Lamarckian" (Kampourakis and Zogza 2007). Broadly, Lamarckian type reasoning in causal explanations of traits involve notions that the use or disuse of organs or body parts leads to heritable changes to organism morphology over generations (Kampourakis and Zogza 2007).

Prevalence of teleological reasoning in children when it comes to explaining changes in organism traits over time, can be overcome with short interventions that target population thinking (e.g. Brown et al. 2020; Emmon et al. 2016). Despite this, educators lament that teleological language appears to prevail among older students and adults (e.g. Barnes et al. 2017; Coley and Tanner 2015; Kelemen and Rosset 2009).

We argue that the challenges related to overcoming these misconceptions, as well as to interpreting student ideas as appropriate vs. inappropriate causal accounts, may stem from the issue that, in gene-centered conceptualizations of evolution, proximate mechanisms (including behavioral variation, behavioral responses to perceived needs, learning, ecological relationships, developmental factors, and reciprocal causation) are de-emphasized in explanations of evolutionary change or of the origins of adaptations. Furthermore, the problem with seemingly Lamarckian-type inheritance or teleological conceptualizations may stem from the fact that inheritance streams beyond genetic inheritance-which people across ages and cultures appear to have an intuitive understanding of (see Moya et al. 2015, and Venville et al. 2005 cited above; Andrews et al. 2011 cited below)-are not being sufficiently elaborated on in the classroom as part of evolutionary explanations and, often, drivers of evolutionary change.

Misconceptions such as teleological reasoning or the notion that traits acquired during development can be passed on to offspring, may be difficult to overcome because it is difficult to "extinguish" or completely replace students' everyday experience of behaviors and needs, their observations of goal-directed behaviors of animals, and their observations that-at least in the human realmwe acquire and transmit many (cognitive, behavioral, and cultural) traits in our lifetime. As Legare and Shtulman (2018) and Chi et al. (2012) point out, different and sometimes seemingly logically inconsistent conceptualizations and schemas may often coexist and be activated for different purposes and in different contexts, including contexts for which these schemas may not be appropriate. Legare and Shtulman (2018) propose that one way to reconcilecoexisting schemas that seem to be inconsistent is to integrate them into a larger causal structure, and they call for research in science education around methods and factors that "promote the construction of integrated, yet scientifically accurate, explanatory models".

In this regard, it is interesting that in the study by Brown et al. (2020), primary school students that held "explicit" teleological notions had higher factual biological knowledge than students that held ambiguous misconceptions. Thus, it seems that the more students learn about a diversity of biological facts throughout development, they need opportunities and supports to integrate their valid conceptions about biology, including about behavioral biology and other proximate causes operating during development, with an account of how such proximate causes combine with genetic inheritance and natural selection to produce adaptations over phylogeny.

Gene-focused conceptualizations of evolution may, currently, not sufficiently support this integration. As Baedke et al. (2020) point out, standard conceptualizations of evolutionary theory stemming from the MS present idealizations, abstracting out developmental processes and proximate interactions. Such idealization may help in understanding broader phylogenetic changes across a range of phenomena, but they may provide rather limited understanding if the interest is in a more concrete account of the role of developmental processes and other proximate mechanisms in explaining particular phenomena. As we also point out in Hanisch and Eirdosh (2020a), we suspect that such idealizations may also wrongfully lead educators to the conclusion that the (idealized, abstracted) conceptualizations of evolution within the framework of the MS represent a more fundamental truth - such that processes operating in development have no causal role in evolutionary change, and student reasoning that references such processes is considered a misconception.

Conversely, generalized conceptions of evolutionary dynamics include and integrate explicitly the roles of developmental factors and proximate mechanisms in bringing about evolutionary change (e.g. Laland et al. 2015; see Hanisch and Eirdosh 2020a). This provides students with opportunities to link their understanding and experiences of proximate mechanisms with evolutionary change. For example, student reasoning that animals respond to needs with behavior, can be productively 
included in causal explanations of evolutionary change through an understanding of the role of behavior as selection pressure or by introducing the concept of niche construction (Mayr 1970; Odlings-Smee et al. 2003). In Hanisch and Eirdosh (2020c), we present a causal mapping teaching tool that allows this integration of proximate and ultimate mechanisms when exploring the causation of behavioral, cognitive, socio-cultural, morphological, and physiological traits during human evolution in secondary school classrooms.

Generalized conceptions of evolutionary dynamics also include and integrate a range of inheritance streams and mechanisms, beyond genetic inheritance (Jablonka and Lamb 2005). This is particularly relevant to the apparent student misconception that acquired traits can be inherited. We argue that discussing the appropriate inheritance mechanisms on a trait by trait basis can help distinguish between correct and incorrect notions about the possible inheritance of acquired traits (see Table 2, Additional file 1). Particularly, novel behavioral traits may well be acquired by animals during their development in response to environmental conditions (called environmental induction, Laland et al. 2015), and those behaviors may in turn be transmitted to offspring as well as others in the population through social learning. Conversely, morphological features that have a strong genetic basis can not be acquired during development and can only be passed on to offspring through genetic inheritance. Many phenotypic traits will develop through complex interactions between various variation producing processes and inheritance mechanisms, including through epigenetic and ecological inheritance (see Hanisch and Eirdosh 2020a).

\section{Addressing challenges of systems thinking}

Evolution educators lament that students have difficulty understanding the complexity and multilevel nature of evolutionary change (Chi et al. 2012; Cooper 2016; Jacobson 2001; Petrosino et al. 2015). Elements of systems thinking include seeing multiple causes rather than single causes, understanding that small causes can have big effects (through delays and non-linear rather than linear cause-effect relationships), understanding that system dynamics result from interactions between elements in the system rather than through central control, and explaining phenomena through emergence rather than through the additive effects of isolated parts (Jacobson 2001; Perkins and Grotzer 2005).

The system concept is often a core concept in biology education standards (e.g. in the Next Generation Science Standards, Achieve 2013). However, our hypothesis is that, while the concept of system may be emphasised in the topics of ecology or physiology in the biology curriculum, in the realm of evolution, an emphasis on genes, on a unidirectional account of selection (from the environment to the organism or to genes), on a centralized notion of "nature selects" (Gregory 2009), as well as on a linear and direct relation between genotype and phenotype may rather stand in the way of applying the concept of system and the complex causality in such systems, to evolution understanding (see Hanisch and Eirdosh 2020b for examples in evolution education standards and materials).

In contrast, generalized and trait-focused conceptualizations of evolution (and development) promote a decentralized view of evolving biological systems, informed by concepts and methods of systems biology and complexity science, by explicitly integrating complex proximate and ecological interactions in evolutionary change. An integration of various interacting factors as causes of phenotypic reconstruction over the course of development, with genes being one type of cause involved in phenotypes, can foster an important aspect of systems thinking (i.e. multiple and reciprocal causality, see Fig. 3).

Furthermore, the ability to use examples of current observable cultural evolutionary change under a more generalized conception of evolution, can serve to highlight complex systems dynamics observable in students' lives, such as the role of feedback loops in fashion trends, the spread of innovations, and "viral" social mediatrends, thus providing opportunities for fostering far transfer of evolutionary dynamics between different domains.

An emphasis on the individual as the primary (and sometimes only) level on which selection occurs, as well as a rather simplified notion of population, abstracting out more complex social group structures and social interdependencies, can also make it challenging for students to understand the concept of multilevel selection, which is required to explain the evolution or emergence of new levels of biological organization in the first place (e.g. Smith and Szathmáry 1995), as well as altruistic and cooperative traits in humans and other organisms (e.g. Wilson 2015). This aspect also has implications for emotional challenges stemming from an overemphasis on competition between (isolated) individuals (see below). A more generalized conception of evolution operating on various levels of biological organization also enables a transfer of the concept of population to the self, as a complex and changing system (e.g. highlighting complex systems dynamics such as feedback involved in phenomena such as homeostasis and behavioral regulation).

Fostering a stronger incorporation of the concept of system in evolution education by integrating interactions of many factors (environmental, social, organism traits, plus genes involved in...) beyond simplified gene-environment interactions, organism-environment 
interactions, or simplified genotype-phenotype relations, in evolving biological systems, may be achieved through the use of causal maps (e.g. Hanisch and Eirdosh 2020c), computer simulations (e.g. Centola et al. 2000; Goldstone and Wilensky 2008); and other teaching tools targeting systems thinking. This system's view on how evolution operates may also address other misconceptions such as teleological reasoning or genetic determinism (see above), as well as emotional and motivational hurdles.

\section{Addressing challenges of evolution acceptance}

The same elements of a trait-centered conception of evolution that might help make progress in evolution understanding as we described in the previous section, might also provide opportunities for making progress in the area of evolution acceptance (Fig. 2).

Table 3 summarizes some of the persistent challenges in evolution education related to evolution acceptance, as mediated by emotional and motivational factors as well as perceived relevance of evolution to student lives. We hypothesize that such challenges may be partly overcome in the following ways:

- Addressing challenges related to perceived relevance of evolution through greater emphasis on observable cultural evolutionary dynamics of human behavior, cognition and culture which are greatly impacting students' world and issues of sustainable development, as well as through integrating student intuitive concepts about change

- Addressing emotional hurdles due to emphasis on competition through greater emphasis on the evolution of cooperative traits, in humans and other species, the role of social interdependence impacting evolutionary trajectories across levels of organization, and exploring the example of self as population for how evolution can favor cooperation among interacting elements

- Addressing emotional hurdles due to emphasis on randomness and passiveness of organisms by greater emphasis on the causal role of goal-directed behavior in shaping evolution, and exploring theevolution and development of our everyday experience, including, sense of purpose, agency, belonging, intention, emotions, explicit goals, and values

- Addressing emotional hurdles due to deterministic and essentialist views of humans by greater emphasis on complex developmental causes of human behavior cognition, and culture, building on student intuitive concepts of adaptation, and relating to self as an evolving system or an evolving population
- Addressing challenges of evolution acceptance due to religious beliefs by focusing on historic and current cultural evolutionary dynamics that do not necessarily conflict with religious beliefs about the past, and by exploring the evolution of religion and morality and other valued behavioral and cultural traits.

\section{Addressing challenges related to perceived relevance of evolution}

Kinchin $(2000,182)$ noted regarding challenges to conceptual change, that "the context associated with the student's alternative framework may be perceived to have greater personal relevance than that associated with the scientifically accepted framework", which will hinder conceptual change. This highlights how conceptual understanding is tightly interlinked with emotional and motivational factors.

To foster a stronger integration of evolution concepts into students' everyday experience, Heddy and Sinatra (2013) and Pugh et al. (2010) employ a transformational approach developed by Pugh and Girod (2007), whereby educators model and make explicit how concepts covered in the classroom can relate to experiences outside the classroom, can expand one's perceptions of the world, and relate to one's values and personal interests. The authors find that these interventions increased conceptual understanding of evolution as well as positive emotions related to evolutionary theory compared to other interventions that target conceptual change but do not focus on these motivational aspects of meaning-making and transfer.

Many biology educators have also pointed out that teaching evolution through human examples or through examples that students experience in their everyday lives, may increase the perceived relevance of evolution understanding to students' lives and thus students' motivation to learn about evolution (Besterman and Baggot la Velle 2007; Nettle 2010; Pobiner 2016; Pobiner et al. 2018; Werth 2009).

However, examples for how evolutionary science affects or can be encountered in students' lives tend to focus on topics such as agricultural breeding, antibiotics resistance or evolutionary medicine-presumably because of the relevance of genetic variation in such examples, or broad ideas about how humans are related to the rest of life (e.g. Barnes et al. 2017; Heddy and Sinatra, 2013; Sinatra et al. 2008). Similarly, regarding the use of human examples, these tend to be constrained to those human traits that have a known and identifiable genetic basis, particularly morphological and physiological traits such as skin color, resistance to disease, lactose tolerance or 


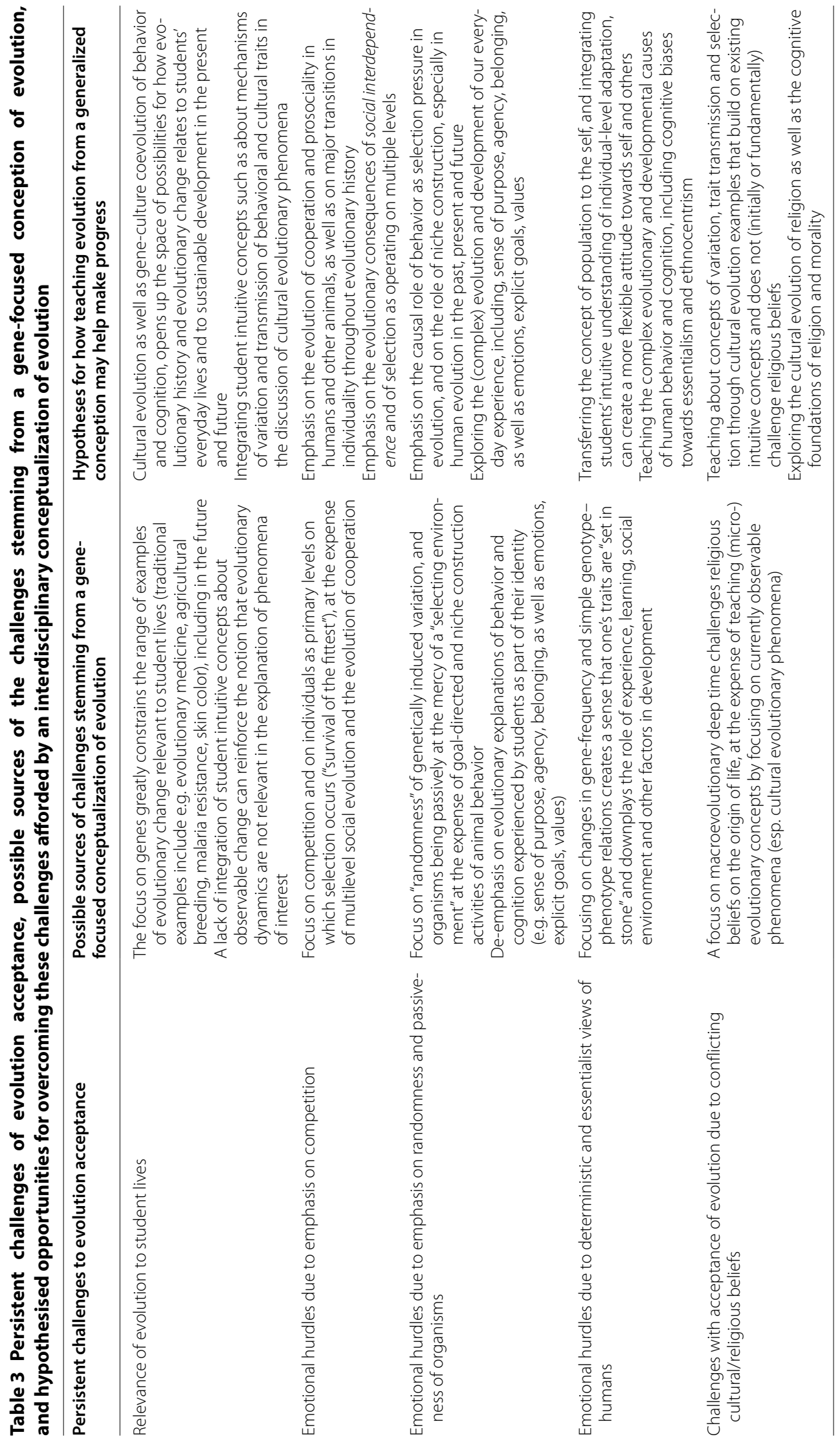


adaptations to high altitudes (e.g. Andrews et al. 2011; Nettle 2010; Pobiner 2016).

In contrast, there seems to be a lack of educational materials and research concerning the (past, present, and future) evolution of human behavior, cognition and culture (Furrow and Hsu 2019; Legare et al. 2018; Ziadie and Andrews 2018). Yet, it is well known that in our species, genetic variation is rather small compared to the large amount of behavioral, cognitive and cultural variation. As Wilson (2005) laments, "One of the biggest tactical errors in teaching evolution is to avoid discussing humans or to restrict discussion to remote topics such as human origins." (Wilson 2005, 1003).

One example of an educational intervention that does explicitly apply evolution to human behavior is an interdisciplinary undergraduate course "Evolution for everyone" (O'Brien et al. 2009; Wilson 2005). Wilson (2005) documented change in students' answers to the question "How much has this class changed your views on evolution and its relevance to human behavior, on a scale from -10 (negative change) to +10 (positive change)?", where the majority of students indicated a large shift in the positive direction. Qualitative answers included phrases like "I have always agreed with evolution but I did not know how much of everyday life was affected by it." and "I came into the class not knowing a lot about evolution. I now have an entirely new outlook on how evolution can be applied to many aspects of life." (p. 1001).

Thus, exploring the evolutionary origins of human behavioral, cognitive and cultural phenotypic diversity in evolution education would greatly expand the available examples of trait variation in our species, with the potential to greatly enhance students' motivation to understand and apply evolutionary theory to many areas in their lives. Classroom discussion can then focus on the mechanisms that produce that variation, and that lead to the selective transmission or inheritance of traits, on a trait by trait basis (see Table 2, Additional file 1). In line with best practices for conceptual learning (see above, Stern et al. 2017), we hypothesize that repeated engagement in such an approach across general education may, in turn, advance conceptual understanding of evolution.

Similarly, a fruitful discussion in the classroom that may spark students' interest and motivation to learn about evolution, is about how humans might continue to evolve in the future. In educational discourse and textbooks (see Hanisch and Eirdosh 2020b), we find that such discussions tend to revolve around genetic changes alone. In contrast, looking at present and future human evolution from the perspective of cultural evolution (including gene-culture coevolution) may be a more relevant lense on how humans will continue to evolve. Arguably cultural evolutionary change will impact students' lives more dramatically and visibly compared to changes in gene frequencies. In this regard, the cultural evolution of sustainability relevant traits (see e.g. Brooks et al. 2018), such as cooperation, moral reasoning, or public health issues, can make evolution education also relevant to sustainability education (see also Eirdosh and Hanisch 2020).

For example, a classroom discussion in Andrews et al. (2011) revolved around whether humans are evolving to become more obese, a trait that was proposed by students, presumably because they are aware of the spread of this trait in society. From the discussion (Andrews et al. 2011, supplemental materials), students are meant to learn that humans are not evolving to become fatter because the trait does not have a purely genetic basis, and humans who are more fat do not have more offspring. However, the concepts of genetic variation, genetic inheritance, and natural selection by differential reproduction would not be sufficient to explain the spread of such a complex phenotypic trait. Instead, from the perspective of a more generalized evolutionary theory, an exploration of the distribution and spread of a trait such as obesity would be more constructive for evolution education by considering a variety of possible mechanisms of inheritance (including social learning and ecological inheritance), as well as a variety of possible mechanisms of differential spread, as in fact already hinted at by the students themselves (see Hanisch and Eirdosh 2020b, for a discussion). In this way, this exploration may be more fruitfully related to issues of public health in human populations, which can help make students more appreciative of the role of evolutionary thinking for addressing real world problems.

Arguably, the lack of educational materials on the evolution and development of human behavior and cognition may stem partly from the scientific and moral questionability of reducing such behavior and cognition to genetics alone. This is achallenge that seems irreconcilable if phenotypes are conceived of as mostly being a direct result of genotypes (see Fig. 3). In contrast, a trait-centered conceptualization of evolution would allow the discussion of the evolution and development of such behavioral, cognitive and cultural traits because the causal factors that lead to such phenotypes explicitly include the social environment, social interactions, social learning and teaching, and other developmental factors. In fact, in the variation of many cultural phenotypes, genetic variation plays hardly any causal role at all (and is at best merely correlated due to common underlying causes such as historic migration patterns). 


\section{Addressing emotional hurdles due to emphasis on competition}

Popular conceptions of evolution as "survival of the fittest" imbue a sense that the theory is all, and perhaps only, about competition among individuals. Across assessment tools and educational standards (see Hanisch and Eirdosh 2020b), we find that the role of competition in evolution, as well as individuals as primary levels on which selection occurs, are emphasised to such a degree, that it might make it challenging to conceive of how altruism and cooperation can evolve. In this regard, Centola et al. (2000, p.166) state that "many students who have been taught to think of individuals as discrete parts of an evolutionary system, have a difficult time understanding how cooperation, or altruistic behavior, could evolve. Because students' intuitions about evolutionary theory have been based on a model of individual success that does not consider the complexity of natural systems, many have had a difficult time re-framing their understanding of evolution." As highlighted above, Brem et al. (2003) found that students overwhelmingly considered that evolution justifies selfish behavior. Such notions, namely a lack of understanding about how evolution can favor cooperative, altruistic or prosocial behaviors in humans and other animals, may indeed affect the degree of evolution acceptance regardless of factors related to religious objections.

In contrast, trait-centered, generalized conceptualizations of evolution are concerned with how evolution operates across all levels of biological organization, and how social structure and social interdependence affect evolutionary dynamics (e.g. Aktipis 1016; Wilson 2015; see Hanisch and Eirdosh 2020a). Such concepts are necessary to understand the evolution of higher biological levels of organizations from lower levels in the first place (e.g. from populations of cells to multicellular organisms; termed major transitions, Smith and Szathmáry 1995), and to understand the evolution of cooperative and prosocial behavior, particularly in the evolutionary history of our own species (e.g. Bowles and Gintis 2011; Tomasello 2009).

Centola et al. (2000) document how undergraduate students from diverse disciplines were able to come to a new understanding about how altruistic behavior could evolve under specific environmental and social conditions by exploring a set of simple agent-based models, concluding that "students became increasingly sensitive to the difficulties of the 'problem' of altruism and were able to meaningfully speculate about the implications of these models for understanding the relevance of altruism and cooperation at a human scale." (p. 173).

Wilson (2005) describes a small classroom activity based on a number of scenarios that quickly allows students to understand how cooperative social behavior that we commonly term "moral" could have evolved and be adaptive, but also how it can be undermined by selfish behavior and therefore be maladaptive. Wilson (2005) states that "When evolutionary theory is presented as a framework for understanding these patterns in all their complexity, including the good, the bad, the beautiful, and the ugly, it is perceived as a tool for understanding that can be used for positive ends, rather than as a threat." (p. 1005).

This understanding of the evolution of cooperation can also be expanded to understand the evolution of multicellularity, thus applying multilevel selection to the individual as a highly integrated population of cooperating elements (e.g. Bonner 2000; Kirk 2005; Pfeiffer and Bonhoeffer 2003).

\section{Addressing emotional hurdles due to emphasis on randomness and passiveness of organisms}

If evolutionarily relevant variation is primarily conceived of stemming from randomly occurring mutations or genetic recombination, this might create emotional and motivational hurdles related to the role (or lack thereof) of one's own actions and choices, as it leaves little room for students to view themselves as active agents of change in how our societies, even our species, might evolve in the future. That is, students may adopt a view that 'my goals, choices, and behaviors ultimately do not matter in how humans will continue to evolve.' Additionally, a certain "existential anxiety" (Legare et al. 2018) may also be reinforced if organisms are largely being portrayed as passively at the mercy of a "selecting environment", rather than as actively involved in changing their environment, through the concepts of niche selection and niche construction. Such notions may underlie findings such as those by Brem et al. (2003), that even among students who "understand" evolution and who have no religious objections to evolution, there are a number of negative attitudes regarding how evolution inhibits self-determination and sense of purpose.

Conversely, trait-centered, generalized conceptualizations of evolution include an explicit causal role of behavior as shaping selection pressures, and emphasize the role of niche construction, that is, organisms actively changing their environmental conditions, which in turn has downstream consequences on evolutionary trajectories (Odling-Smee et al. 2003). This is especially relevant in human evolution (e.g. O'Brien and Laland 2012; Zeder 2016). Integrating and emphasising the role of our own behaviors and choices and of cultural evolutionary dynamics when reflecting on present and future human evolution may contribute to creating a more active stance and a higher motivation in students to understand how 
their choices and actions can shape evolutionary dynamics. That is, students may adopt a view that 'my goals, choices, and behaviors matter in how humans will continue to evolve'.

Additionally, a gene-focused conceptualization of evolution makes it difficult to explore the evolutionary and developmental origins of human behavioral and cognitive traits experienced by students as part of their identity (sense of purpose, sense of belonging, sense of intention and control, emotions, language, music, explicit goals, values), presumably because such traits can not be easily explained by genetic variation and inheritance alone. Conversely, trait-centered, generalized conceptualizations of evolution allow the exploration of the evolution and development of our everyday experience, as emerging from complex interactions between genes, socio-cultural environment, and interactions among phenotypic traits during development (see Fig. 3).

\section{Addressing emotional hurdles due to deterministic and essentialist views of humans}

Another set of challenges relates to social-emotional learning and students' attitudes towards themselves and others. We argue that focusing on changes in gene-frequency and simple genotype-phenotype relations may create a sense that one's traits are rather "set in stone" from birth and downplays the role of experience, learning, social environment, behavioral flexibility and other factors operating during development. This challenge is therefore also related to the cognitive biases of essentialist thinking and genetic determinism (see above), applied to the self, as well as the problem that students' intuitive understanding of individuals being able to adapt is considered a misconception (see above).

Instead, it may be valuable to drive students' reflection on their experience of being able to change, vary their behaviors, try out and learn new things, and of being able to (consciously) influence which kinds of behaviors they should "retain" into their (significantly unconscious) behavioral repertoire (see Table 2). Such an approach may be particularly critical as these processes underpin important educational constructs of social-emotional learning, such as growth mindset(Haimovitz and Dweck 2017) and psychological flexibility (Hayes et al. 2012; Kashdan and Rottenberg 2010). In this regard, transfering the concepts of population and complex system to the self can create a more flexible attitude towards self and others, as this mindset about the self is also considered a key process involved in mental health (Hayes et al. 2012; see Eirdosh and Hanisch 2020; Hanisch and Eirdosh 2020a).

Additionally, a more flexible attitude towards the self may also contribute to alleviating the problem of racist or ethnocentric thinking towards groups of other humans, a concern that is particularly relevant to how we teach about evolution (e.g. Kattmann 2010). This aspect highlights that teachers need guidance in how to prevent misinterpretations of evolution which embolden ethnocentric thinking.

In this regard, current approaches to tackle racism within the biology curriculum tend to focus on addressing the invalid notion of "race" from a biological perspective based on the low genetic variation in our species. We argue that this approach may not be very effective and perhaps even problematic, because it does not tackle the causes of ethnocentric thinking itself. Logically, it seems to invite the inference that, if genetic variation across groups of humans were indeed larger, racism would therefore be justified.

Instead, we argue that a generalized notion of evolution can help address racism in two ways. One way is through a focus on the traits that are common to all humans and on the complex developmental causality of human behavioral, cognitive and cultural phenotypes. In fact, cultural evolution models for the inheritance and spread of human behavioral, cognitive, cultural traits have precisely challenged the notion that certain traits (such as IQ, Cavalli-Sforza and Feldmann 1973) have a purely genetic basis-a notion which has been the basis of eugenic ideas about the superiority of certain ethnicities. Another way to address ethnocentrism within evolution education is to explore the evolutionary and developmental origins of human ethnocentric tendencies as well as ways to overcome them. This can be achieved in the classroom by exploring a range of developmental and cross-cultural research that highlights the human tendency to favor those who are similar to oneself in various, often superficial and arbitrary, traits (e.g. Hamlin et al. 2013). Furthermore, explaining the evolution of ethnocentric behavior can benefit from concepts in multilevel selection since it involves accounting for inclusive fitness, and can be explored in the classroom with the help of agent-based computer simulations (Hammond and Axelrod 2006; Wilensky 2003).

Exploring this content can help students become more aware of such tendencies and their causes, and subsequent discussions can focus on the implications for current society, and on various approaches and opportunities for overcoming such biases as individuals and as communities (see e.g., OpenMind Platform, Inc., 2020, for a successful evidence-based implementation of such an educational approach).

\section{Addressing challenges with religious beliefs}

Evolution education has a particular challenge regarding the acceptance of evolutionary theory due to perceived conflicts with individual beliefs about origins of life. As 
we highlighted above, while progress has been made in terms of increasing acceptance of evolution by teachers and the identification of effective approaches to help students and teachers reconcile evolutionary theory with their beliefs, there are still substantial challenges of acceptance, that in turn may hinder a conceptual understanding of evolutionary concepts.

We hypothesize that a generalized conception of evolution that includes cultural evolution, may allow the teaching about microevolutionary processes and concepts of variation, trait transmission and selection of historic and currently observable phenomena (esp. cultural evolutionary phenomena) without (initially or fundamentally) challenging religious beliefs about the past, and integrating student intuitive ideas about change. Even if acceptance of macroevolutionary facts about the past may be difficult to achieve, we may still be able to develop in students, regardless of their beliefs, understanding about concepts in evolutionary change, and this understanding may in turn enable a more open stance towards transferring concepts of cultural evolution to biological evolution.

Further, as discussed across multiple sections above, the potential to engage students in understanding the cultural evolution of sustainability relevant traits, morality and prosociality, and valued goal-directed behaviors may speak to the virtues and values of religious communities, and reduce concerns that evolutionary theorizing implies a justification of unethical behaviors (see e.g. Brem et al. 2003; Wilson 2005).

\section{Is evolution education climbing the wrong mountain?}

Evolution education continues to struggle with the range of persistent challenges to understanding and acceptance as outlined in this article. While some progress is being made as we highlighted above, we argue that the constraints provided by a gene-centered conceptualization of evolution may inherently limit the degree to which the evolution education community might make progress on these specific aims.

Remaining exclusively committed to the idealized, gene-focused ways of evolution conceptualization in standards, instructional methods, and assessment tools constrains pedagogical variation in such a way that it may well prove to keep the evolution education community stuck in a "local maximum" in the educational fitness landscape. While progress might be made on the way by tinkering with small variations of traditionally held conceptualizations, that same trajectory might end up removing the community more and more from reaching a more global peak, both for understanding and acceptance, that is potentially presented by an interdisciplinary evolution education (Fig. 4).

Enabling the evolution education community to reach its actual goals of wide-spread evolution understanding and acceptance in the classroom and in the wider public may thus require a leap into uncertain terrain. Relative to the familiar paths of existing methods and conceptualizations, this emerging landscape requires exploring new variations of educational approaches and new variations of research and assessment tools. But without such a leap, we are skeptical that the community will really be able to take advantage of the actual advances, in terms of conceptual clarity, nature of science lessons, applied value to students' everyday life, and to shaping the future

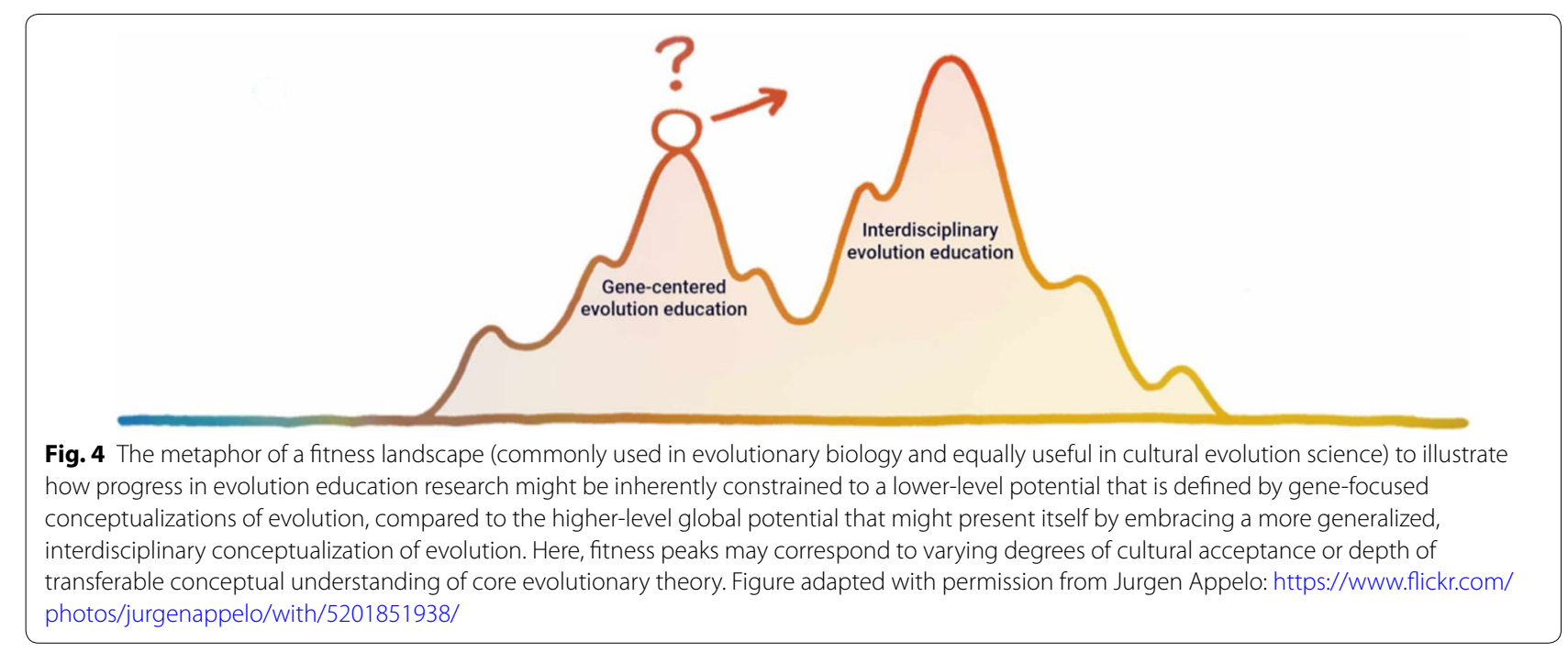


evolution of our species, that evolutionary science itself is providing in the 21 st century.

\section{Outlook}

We have outlined a number of hypotheses for how teaching evolution through a more generalized conception, informed by current discourse in interdisciplinary evolutionary science, may help overcome a range of persistent challenges in evolution education. This applies to evolution education more broadly, but especially to the treatment of human evolution, where many gains could be made, in terms of advancing an integrated and transferable conceptual understanding of how evolution operates across domains and levels, and in terms of advancing the perceived relevance of evolutionary theory to students' lives by incorporating the exploration of behavioral, cognitive, and cultural traits.

We recognize that empirical investigations of the validity of our hypotheses are a large endeavour, for which cooperation among many educators and researchers will be needed. Towards this aim, we have advanced a range of teaching and assessment tools as well as scientific content to engage teachers and students in generalized conceptualizations of evolution, with preliminary evidence of the learning potential in classrooms. Specifically, we have initiated and suggest the need for continued development of:

- The use of causal maps to highlight and reflect on the role of proximate mechanisms and complex causal interactions between natural environment, social environment, behavior, body features, brains, genes, and culture in development and evolution. Preliminary evidence from 10th and 12th grade classroom interventions indicates that causal maps can serve as an effective tool for reflection and discussion of complex causes of human behavior and cognition (Hanisch and Eirdosh 2020c);

- The use of analogy maps to discuss and practice the transfer of concepts in evolution between different conceptualizations or different domains (e.g. genes vs. culture vs. individual learning; see Table 2 and Additional file 1). With the help of such analogy maps, students' existing understanding about evolutionary concepts can be fruitfully expanded and deepened by transferring concepts from genetic evolution to other domains, or vice versa;

- The use of computer simulations to advance transferable understandings of concepts and processes in evolution (see e.g., Centola et al. 2000; Goldstone and Wilensky, 2008);

- Stronger integration of behavioral, cognitive, and cultural science perspectives, in addition to classic foci of genetics and archeology, in teaching about human evolution. Specifically, cross-species, cross-development and cross-cultural behavioral experiments and observations provide a wealth of largely untapped potential for the development of educational content (see Global ESD, 2020). Engaging such content may help identify a number of misconceptions about human behavior (see e.g. Hanisch and Eirdosh, in press), and at the same time may provide transformative experiences (sensu Pugh 2011) in the evolution education classroom, by allowing students to make connections to their everyday experience, extend their understanding, and explore implications for sustainable development.

While highlighting these potential pathways to overcoming persistent challenges in evolution education, we recognize that teaching evolution from a trait-centered, generalized, and interdisciplinary conceptualization may be met with skepticism and various objections. For example, the structure of school subjects and educational standards is currently such that it makes it difficult to explore the interdisciplinary nature of evolutionary theory in classrooms, particularly in relation to human sciences. In the US, the Next Generation Science Standards (Achieve 2013) explicitly exclude the human behavioral sciences from their framework (National Research Council 2012), while the social studies state standards (National Council for the Social Studies 2013) do not include the biological study of human behavior as part of the disciplinary core concepts.

Our claim is only that the evolution education research and development community should be actively engaged in this timely discussion around the educational value of an interdisciplinary evolutionary science, towards shaping the future curriculum. Overall, our project, Teaching evolution as an interdisciplinary science, aims to clarify the scientific landscape, learning potential, and challenges of moving in this direction. We feel there is a significant case for much broader engagement across the evolution education and other disciplinary education communities about the issues identified here. The role of interdisciplinary evolutionary theory in helping our species explore ways to adapt sustainably into the future is too important to not be taken seriously by educators. We encourage readers to join us in advancing this discussion.

\section{Supplementary information}

Supplementary information accompanies this paper at https://doi org/10.1186/s12052-020-00138-4.

Additional file 1: Comparison cultural evolution and genetic evolution. LessonPlan. 


\section{Abbreviation}

MS: Modern synthesis.

\section{Acknowledgements}

This article is part of a wider educational project by the authors on teaching evolution as an interdisciplinary science. See the project page on OSF: https:// osf.io/u6rd5/.

\section{Authors' contributions}

SH and DE developed the concept of the article. SH lead the writing of the manuscript. Both authors read and approved the final manuscript.

\section{Funding}

DE received funding from the Max Planck Institute for evolutionary anthropology, department of comparative cultural psychology, for this work.

\section{Availability of data and materials}

Not applicable.

\section{Competing interests}

The authors declare that they have no competing interests.

\section{Author details}

1 Department of Comparative Cultural Psychology, Max Planck Institute for Evolutionary Anthropology, Leipzig, Germany. ${ }^{2}$ Department of Primary School Science Education, University of Leipzig, Leipzig, Germany. ${ }^{3}$ Global ESD, Elkins Park, USA. ${ }^{4}$ EvoLeipzig, Leipzig, Germany.

Received: 4 July 2020 Accepted: 11 November 2020 Published online: 04 December 2020

\section{References}

Achieve. Topic Arrangements of the Next Generation Science Standards. Retrieved from https://www.nextgenscience.org/sites/default/files/ AllTopic.pdf (2013).

Anderson DL, Fisher KM, Norman GJ. Development and evaluation of the conceptual inventory of natural selection. J Res Sci Teaching. 2002;10(10):952-78. https://doi.org/10.1002/tea.10053.

Andrews TM, Kalinowski ST, Leonard MJ. Are humans evolving?" a classroom discussion to change student misconceptions regarding natural selection. Evol Edu Outreach. 2011;4(3):456-66. https://doi.org/10.1007/ s12052-011-0343-4.

Apodaca MJ, Mclnerney JD, Sala OE, Katinas L, Crisci JV. A concept map of evolutionary biology to promote meaningful learning in biology. Am Biol Teacher. 2019;81(2):79-87. https://doi.org/10.1525/abt.2019.81.2.79.

Araújo LAL. The centrality of evolution in biology teaching: towards a pluralistic perspective. J Biol Edu. 2020;00(00):1-12. https://doi. org/10.1080/00219266.2020.1757486.

Aubusson PJ, Harrison AG, Ritchie SM. Metaphor and Analogy in Science Education. Dordrecht: Springer; 2006. https://doi. org/10.1007/1-4020-3830-5_1.

Baedke J, Fábregas-Tejeda A, Vergara-Silva F. Does the extended evolutionary synthesis entail extended explanatory power? Biol Philos. 2020;35(1):122. https://doi.org/10.1007/s10539-020-9736-5.

Barnes ME, Evans EM, Hazel A, Brownell SE, Nesse RM. Teleological reasoning, not acceptance of evolution, impacts students' ability to learn natural selection. Evolution Edu Outreach. 2017;10(1):7. https://doi. org/10.1186/s12052-017-0070-6.

Barnett SM, Ceci SJ. When and where do we apply what we learn? A taxonomy for far transfer. Psychol Bull. 2002;128(4):612-37. https://doi. org/10.1037/0033-2909.128.4.612.

Bertka CM, Pobiner B, Beardsley P, Watson WA. Acknowledging students' concerns about evolution: a proactive teaching strategy. Evol Edu Outreach. 2019. https://doi.org/10.1186/s12052-019-0095-0.

Besterman H, Baggot la Velle L. Using human evolution to teach evolutionary theory. J Biol Edu. 2007;41(2):76-81. https://doi.org/10.1080/00219 266.2007.9656066.

Bonner JT. First signals: the evolution of multicellular development. Princeton: Princeton University Press; 2000.
Bowles S, Gintis H. A cooperative species. Human reciprocity and its evolution. Princeton: Princeton University Press; 2011.

Brem SK, Ranney M, Schindel J. Perceived consequences of evolution: college students perceive negative personal and social impact in evolutionary theory. Sci Edu. 2003;87(2):181-206. https://doi.org/10.1002/sce.10105.

Brooks JS, Waring TM, Borgerhoff Mulder M, Richerson PJ. Applying cultural evolution to sustainability challenges: an introduction to the special issue. Sustainability Sci. 2018;13(1):1-8. https://doi.org/10.1007/s1162 5-017-0516-3.

Cavalli-Sforza LL, Feldman MW. Cultural versus biological inheritance: phenotypic transmission from parents to children (a theory of the effect of parental phenotypes on children's phenotypes). Am J Human Genetics. 1973; 25(6): 618-637. https://www.ncbi.nlm.nih.gov/pmc/articles/ PMC1762580/\#

Centola D, Wilensky, U, McKenzi, E. A hands-on modeling approach to evolution: Learning about the evolution of cooperation and altruism through multi-agent modeling-The EACH Project. In Proceedings of the Fourth International Conference of the Learning Sciences (pp. 166-173). 2000. Mahwah: Erlbaum.

Chi MTH, Kristensen AK, Roscoe RD. Misunderstanding emergent causal mechanism in natural selection. In: Rosengren K, Brem SK, Evans EM, Sinatra $G M$, editors. Evolution challenges: integrating research and practice in teaching and learning about evolution. Oxford: Oxford University Press; 2012. p. $145-73$

Chudek M, Henrich J. Culture-gene coevolution, norm-psychology and the emergence of human prosociality. Trends Cogn Sci. 2011;15(5):218-26. https://doi.org/10.1016/j.tics.2011.03.003.

Coley JD, Tanner K. Relations between intuitive biological thinking and biological misconceptions in biology majors and nonmajors. CBE Life Sci Edu. 2015;14(1):1-19. https://doi.org/10.1187/cbe.14-06-0094.

Cooper RA. Natural selection as an emergent process: instructional implications. J Biol Edu. 2016;51(3):247-60. https://doi.org/10.1080/00219 266.2016.1217905.

Cultural Evolution Society (2020). What is cultural evolution?. https://culturalev olutionsociety.org/story/What_is_Cultural_Evolution. Accessed on 4 August 2020.

Deniz H, Borgerding LA. Evolution Education Around the Globe. $(H$. Deniz, LA. Borgerding, Eds.). Cham: Springer. 2018

Duncan RG, Rogat AD, Yarden A. A learning progression for deepening students' understandings of modern genetics across the 5th- 10thgrades. J Res Sci Teaching. 2009;46(6):655-74. https://doi.org/10.1002/tea.20312.

Dunk RDP, Barnes ME, Reiss MJ, Alters B, Asghar A, Carter BE, Wiles JR. Evolution education is a complex landscape. Nature Ecol Evolution. 2019. https:// doi.org/10.1038/s41559-019-0802-9.

Eirdosh D, Hanisch S. Can the science of Prosocial be a part of evolution education? Evolution Edu Outreach. 2020. https://doi.org/10.1186/s1205 2-020-00119-7.

Emmons NA, Smith H, Kelemen D. Changing minds with the story of adaptation: strategies for teaching young children about natural selection. Early Edu Develop. 2016;9289:1-17. https://doi.org/10.1080/10409 289.2016.1169823.

Evans EM, Rosengren K. Cognitive Biases or Cognitive Bridges? Intuitive Reasoning in Biology. In K Kampourakis, MJ. Reiss (Eds.), Teaching Biology in Schools. Global Research, Issues, and Trends. New York: Routledge. 2018. https://doi.org/10.4324/9781315110158

Fuenetes A. Leading with complexity in evolution education. Global ESD blog at NPJ Science of Learning Community. 2020 https://go.natur e.com/2AfknVO

Furrow RE, Hsu JL. Concept inventories as a resource for teaching evolution. Evol Edu Outreach. 2019. https://doi.org/10.1186/s12052-018-0092-8.

Gelman SA. The essential child: origins of essentialism in everyday thought. Oxford: Oxford University Press; 2003.

Gentner D, Holyoak KJ, Kokinov BK. The analogical mind. Perspectives from cognitive science. Cambridge: MIT Press; 2001.

Gentner D, Loewenstein J, Thompson L. Analogical Encoding: Facilitating Knowledge Transfer and Integration. Twenty-Sixth Annual Meeting of the Cognitive Science Society. 2004.

Gintis $\mathrm{H}$. The bounds of reason. Game theory and the unification of the behavioral sciences. Princeton: Princeton University Press; 2009

Global ESD (2020). Classroom materials. http://teaching-materials.GlobalESD. org 
Glynn SM. Making science concepts meaningful to students: teaching with analogies. In: Mikelskis-Seifert S, Ringelband U, Brückmann M, editors. Four decades of research in science education: from curriculum development to quality improvement. Münster: Waxmann; 2008. p. 113-25.

Goldstone RL, Wilensky U. Promoting transfer by grounding complex systems principles. J Learning Sci. 2008;17(4):465-516. https://doi. org/10.1080/10508400802394898.

Gouvea JS, Simon MR. Challenging cognitive construals: a dynamic alternative to stable misconceptions. Life Sci Educ. 2018. https://doi.org/10.1187/ cbe.17-10-0214

Greaves M. Nothing in cancer makes sense except. BMC Biol. 2018;16(1):1-8. https://doi.org/10.1186/s12915-018-0493-8.

Graf D, Schmidt-Salomon M. EvoKids-Evolution in der Grundschule. 2nd ed. Oberwesel/Gießen: Giordano-Bruno-Stiftung; 2017.

Gregory TR. Understanding natural selection: essential concepts and common misconceptions. Evol Edu Outreach. 2009;2(2):156-75. https://doi. org/10.1007/s12052-009-0128-1.

Haimovitz K, Dweck CS. The origins of children's growth and fixed mindsets: new research and a new proposal. Child Develop. 2017;88(6):1849-59. https://doi.org/10.1111/cdev.12955.

Hammond RA, Axelrod R. The evolution of ethnocentrism. J Conflict Resol. 2006;50(6):926-36. https://doi.org/10.1177/0022002706293470.

Hamlin JK, Mahajan N, Liberman Z, Wynn K. Not like me = bad: Infants prefer those who harm dissimilar others. Psych. Sci. 2013;24(4):589-94. https:// doi.org/10.1177/0956797612457785

Hanisch S, Eirdosh D. Conceptual clarification of evolution as an interdisciplinary science. EdArXiv. 2020. https://doi.org/10.35542/osf.io/vr4t5.

Hanisch S, Eirdosh D. (2020b). Challenges with conceptualizations of evolution in biology education. Preprint. https://doi.org/10.13140/RG.2.2.26589 .64484

Hanisch S, Eirdosh D. Causal mapping as a teaching tool for reflecting on causation in human evolution. Sci Edu. (in press).

Hanisch S, Eirdosh D. (in review). Are human a cooperative species? Challenges and opportunities for teaching the evolution of human prosociality. The American Biology Teacher.

Hare BA, Wobber V, Wrangham R. The self-domestication hypothesis: evolution of bonobo psychology is due to selection against aggression. Animal Behav. 2012;83(3):573-85. https://doi.org/10.1016/j.anbeh av.2011.12.007.

Harms U, Reiss MJ. Evolution Education Re-considered. Understanding What Works. (U Harms, MJ Reiss, Eds.), Evolution Education Re-considered. Cham: Springer. 2019

Harrison AG, Treagust DF. Teaching and Learning with Analogies: Friend or foe? In: Aubusson PJ, Harrison, AG, Ritchie SM. Metaphor and Analogy in Science Education. Dordrecht: Springer. 2006. https://doi. org/10.1007/1-4020-3830-5 1

Haskell RE. Transfer of learning. Cognition, instruction, and reasoning. Newyork: Academic Press. 2000

Hayes SC, Sanford BT. Modern psychotherapy as a multidimensional multileve evolutionary process. Current Opin Psychol. 2015;2(May):16-20. https:// doi.org/10.1016/j.copsyc.2015.01.009.

Hayes SC, Strosahl KD, Wilson KG. Acceptance and commitment therapy. The process and practice of mindful change. 2nd ed. New York: The Guilford Press; 2012.

Heddy BC, Sinatra GM. Transforming misconceptions: using transformative experience to promote positive affect and conceptual change in students learning about biological evolution. Sci Edu. 2013;97(5):723-44. https://doi.org/10.1002/sce.21072.

Henrich J. The secret of our success. How culture is driving human evolution, domesticating our species, and making us smarter. Princeton, Oxford: Princeton University Press. 2016.

Herrmann E, Call J, Hernandez-Lloreda MV, Hare BA, Tomasello M. Humans have evolved specialized skills of social cognition: the cultural intelligence hypothesis. Science. 2007;317(5843):1360-6. https://doi. org/10.1126/science.1146282.

Heyes CM. Cognitive Gadgets. The cultural evolution of thinking. Cambridge: Harvard University Press; 2018.

Hiatt A, Davis GK, Trujillo C, Terry M, French DP, Price RM, Perez KE. Getting to evo-devo: concepts and challenges for students learning evolutionary developmental biology. CBE Life Sci Edu. 2013;12(3):494-508. https:// doi.org/10.1187/cbe.12-11-0203.
Hofstadter DR. Epilogue. Analogy as the Core of Cognition. In: Gentner, D., Holyoak, K. J., \& Kokinov, B. K. (2001). The analogical mind. Perspectives from cognitive science. Cambridge: MIT Press, (2001).

Hoppitt W, Laland K. Social learning: an introduction to mechanisms, methods, and models. Princeton: Princeton University Press; 2013.

Jablonka E, Lamb MJ. Evolution in four dimensions. Genetic, epigenetic, behavioral, and symbolic variation in the history of life. Cambridge, MIT Press. 2005

Jablonka E, Ginsburg S, Dor D. The co-evolution of language and emotions. Philos Trans Royal Society B Biol Sci. 2012;367(1599):2152-9. https://doi. org/10.1098/rstb.2012.0117.

Jacobson MJ. Problem solving, cognition, and complex systems: differences between experts and novices. Complexity. 2001;6(3):41-9. https://doi. org/10.1002/cplx.1027.

Jamieson A, Radick G. Genetic determinism in the genetics curriculum: an exploratory study of the effects of mendelian and weldonian emphases. Sci Edu. 2017;26(10):1261-90. https://doi.org/10.1007/s1119 1-017-9900-8.

Kalinowski ST, Leonard MJ, Taper ML. Development and validation of the Conceptual Assessment of Natural Selection (CANS). CBE Life Sci Edu. 2016. https://doi.org/10.1187/cbe.15-06-0134.

Kampourakis K, Zogza V. Students' preconceptions about evolution: how accurate is the characterization as "Lamarckian" when considering the history of evolutionary thought? Science Edu. 2007;16(3-5):393-422. https://doi.org/10.1007/s11191-006-9019-9.

Kashdan TB, Rottenberg J. Psychological flexibility as a fundamental aspect of health. Clin Psychol Rev. 2010;30(7):865-78. https://doi.org/10.1016/j. cpr.2010.03.001

Kattmann, U. (2010). Race, genes, and racism. Graz (Proceedings of the First Conference on Applied Interculturality Research, 7-10 April 2010).

Kelemen D. (2012). Teleological minds: How natural intuitions about agency and purpose influence learning about evolution. In KS Rosengren, SK Brem, EM Evans, GM. Sinatra (Eds.), Evolution challenges: integrating research and practice in teaching and learning about evolution. Oxford University Press.

Kelemen D, Emmons NA, Seston Schillaci R, Ganea PA. Young children can be taught basic natural selection using a picture-storybook intervention. Psychol Sci. 2014;25(4):893-902. https://doi.org/10.1177/0956797613 516009.

Kelemen D, Rosset E. The human function compunction: teleological explanation in adults. Cognition. 2009;111(1):138-43. https://doi.org/10.1016/j. cognition.2009.01.001.

Kinchin IM. From "ecologist" to "conceptual ecologist": the utility of the conceptual ecology analogy for teachers of biology. J Biol Edu. 2000;34(4):17883. https://doi.org/10.1080/00219266.2000.9655715.

Kirk DL. A twelve-step program for evolving multicellularity and a division of labor. BioEssays. 2005;27(3):299-310. https://doi.org/10.1002/bies.20197

Kirschner PA, Hendrick C. How learning happens. Seminal works in educational psychology and what they mean in practice. Society. New York Routledge. 2020.

Lake MW, Venit J. Quantitative Analysis of Macroevolutionary Patterning in Technological Evolution. Bicycle Design from 1800 to 2000. In: Shennan SJ. (ed). Pattern and Process in Cultural Evolution. (S. J. Shennan, Ed.). Berkeley, California, USA: University of California Press. (pp. 147-161). 2009

Laland KN, Odling-Smee J, Myles S. How culture shaped the human genome: bringing genetics and the human sciences together. Nat Rev Genetics. 2010;11(2):137-48. https://doi.org/10.1038/nrg2734.

Laland KN, Sterelny K, Odling-Smee J, Hoppitt WJE, Uller T. Cause and effect in biology revisited: is Mayr's proximate-ultimate dichotomy still useful? Science. 2011;334(6062):1512-6. https://doi.org/10.1126/science.12108 79.

Laland KN, Uller T, Feldman MW, Sterelny K, Müller GB, Moczek AP, OdlingSmee J. The extended evolutionary synthesis: its structure, assumptions and predictions. Proc R Soc B. 2015;282(1813):20151019. https://doi. org/10.1098/rspb.2015.1019.

Legare CH, Lane JD, Evans EM. Anthropomorphizing science: how does it affect the development of evolutionary concepts? Merrill-Palmer Quarterly. 2013;59(2):168-97. https://doi.org/10.1353/mpq.2013.0009. 
Legare CH, Opfer JE, Busch JTA, Shtulman A. A field guide for teaching evolution in the social sciences. Evolution Human Behavior. 2018;39(3):25768. https://doi.org/10.1016/j.evolhumbehav.2018.01.002.

Legare $\mathrm{CH}$, Shtulman A. Explanatory pluralism across cultures and development. Metacog Divers Interdiscip Approach. 2018. https://doi. org/10.1093/oso/9780198789710.003.0019.

Levinson SC, Gray RD. Tools from evolutionary biology shed new light on the diversification of languages. Trends Cogn Sci. 2012;16(3):167-73. https ://doi.org/10.1016/j.tics.2012.01.007.

Love AC. Interdisciplinary lessons for the teaching of biology from the practice of evo-devo. Sci Edu. 2013;22(2):255-78. https://doi.org/10.1007/s1119 1-011-9351-6.

MacCallum RM, Mauch M, Burt A, Leroi AM. Evolution of music by public choice. PNAS Proceed Natl Acad Sci. 2012;109(7):1-6. https://doi. org/10.1073/pnas.1203182109.

Mayr E. Populations, species, and evolution. An abridgment of animal species and evolution. Cambridge, MA: Harvard University Press. 1970.

McElreath R, Boyd RT. Mathematical models of social evolution. A guide for the perplexed. Chicago: University of Chicago Press; 2007.

Mead R, Hejmadi M, Hurst LD. Teaching genetics prior to teaching evolution improves evolution understanding but not acceptance. PLoS Biol. 2017;15(5):1-30. https://doi.org/10.1371/journal.pbio.2002255.

Mesoudi A. Cultural evolution: how darwinian theory can explain human culture and synthesize the social sciences. Chicago: University of Chicago Press; 2011.

Moya C, Boyd R, Henrich J. Reasoning about cultural and genetic transmission: developmental and cross-cultural evidence from Peru, Fiji, and the United States on how people make inferences about trait transmission. Topics Cogn Sci. 2015;7(4):595-610. https://doi.org/10.1111/tops.12163.

National Council for the Social Studies. (2013). The College, Career, and Civic Life (C3) Framework for Social Studies State Standards: Guidance for Enhancing the Rigor of K-12 Civics, Economics, Geography, and History. Silver Spring, MD, USA: National Council for the Social Studies. Retrieved from https://www.socialstudies.org/sites/default/files/c3/c3-frame work-for-social-studies-rev0617.pdf

National Research Council. (2012). A Framework for K-12 Science Education: Practices, Crosscutting Concepts, and Core Ideas. Committee on a Conceptual Framework for New K-12 Science Education Standards. Board on Science Education, Division of Behavioral and Social Sciences and Education. Washington, DC: The National Academies Press.

Nehm RH, Poole TM, Lyford ME, Hoskins SG, Carruth L, Ewers BE, Colberg PJS. Does the segregation of evolution in biology textbooks and introductory courses reinforce students' faulty mental models of biology and evolution? Evol Edu Outreach. 2009;2(3):527-32. https://doi. org/10.1007/s12052-008-0100-5.

Nehm RH, Ha M, Rector M, Opfer J, Perrin L, Ridgway J, Mollohan K. Scoring Guide for the Open Response Instrument (ORI) and Evolutionary Gain and Loss Test (EGALT). Technical Report of National Science Foundation REESE Project 0909999. 2010

Nehm RH, Beggrow EP, Opfer JE, Ha M. Reasoning about natural selection: diagnosing contextual competency using the ACORNS instrument. Am Biol Teacher. 2012;74(2):92-8. https://doi.org/10.1525/abt.2012.74.2.6.

Nettle D. Understanding of evolution may be improved by thinking about people. Evolu Psychol. 2010;8(2):147470491000800. https://doi. org/10.1177/147470491000800206.

O'Brien DT, Gallup AC. Using Tinbergen's four questions (Plus One) to facilitate evolution education for human-oriented disciplines. Evolution Edu Outreach. 2011;4(1):107-13. https://doi.org/10.1007/s12052-010-0305-2.

O'Brien DT, Wilson DS. Using 'Evolution for Everyone 'as a Guide for New General Education Courses in Evolution. The EvoS Journal. 2(1), 1-11. 2010. Retrieved from http://www.evostudies.org/pdf/O'BrienVol2lss 1.pdf

O'Brien DT, Wilson DS, Hawley PH. Evolution for everyone: a course that expands evolutionary theory beyond the biological sciences. Evol Edu Outreach. 2009;2(3):445-57. https://doi.org/10.1007/s1205 2-009-0161-0

O'Brien MJ, Laland KN. Genes, culture, and agriculture an example of human niche construction. Curren Anthropol. 2012;53(4):434-70. https://doi. org/10.1086/666585.

Odling-Smee J, Laland KN, Feldman MW. Niche construction. The neglected process in evolution. Princeton: Princeton University Press; 2003.
Ojalehto B, Waxman, SR, Medin DL. Teleological reasoning about nature: Intentional design or relational perspectives? Trends Cogn Sci. 2013;17(4):166-71. https://doi.org/10.1016/j.tics.2013.02.006.

Ojalehto B, Waxman SR, Medin DL. Teleological reasoning about nature: Intentional design or relational perspectives. Trends Cognitive Sci. 2013;17(4):166-71. https://doi.org/10.1016/j.tics.2013.02.006.

OpenMind Platform, Inc. (2020). OpenMind. An interactive platform that equips people with a set of practical tools to think clearly and communicate constructively across differences. https://openmindplatform.org/

Opfer JE, Nehm RH, Ha M. Cognitive foundations for science assessment design: knowing what students know about evolution. J Res Sci Teaching. 2012;49(6):744-77. https://doi.org/10.1002/tea.21028.

Oyama S, Griffiths PE, Gray RD. Cycles of contingency. Developmental systems and evolution. Cambridge: MIT Press; 2001.

Pérez I, Janssen MA. The effect of spatial heterogeneity and mobility on the performance of social-ecological systems. Ecolo Modell. 2015;296:1-11. https://doi.org/10.1016/j.ecolmodel.2014.10.014.

Perkins DN, Grotzer TA. Dimensions of causal understanding: the role of complex causal models in students' understanding of science. Stud Sci Edu. 2005;41(1):117-66. https://doi.org/10.1080/03057260508560216.

Petrosino AJ, Lucero MM, Mann MJ. Decentralized thinking and understanding of evolution in K-12 evolution education. Evolution Edu Outreach. 2015;8(1):2. https://doi.org/10.1186/s12052-014-0028-x.

Pfeiffer T, Bonhoeffer S. An evolutionary scenario for the transition to undifferentiated multicellularity. Proceed National Academy Sci. 2003;100(3):1095-8. https://doi.org/10.1073/pnas.0335420100.

Plutzer E, Branch G, Reid A. Teaching evolution in US public schools: a continuing challenge. Evolution Edu Outreach. 2020;13(1):1-15. https://doi. org/10.1186/s12052-020-00126-8.

Pobiner B. Accepting, understanding, teaching, and learning (human) evolution: Obstacles and opportunities. Am J Physical Anthropol. 2016;159:S232-74. https://doi.org/10.1002/ajpa.22910.

Pobiner B, Beardsley PM, Bertka CM, Watson WA. Using human case studies to teach biology classrooms. Evolution Edu Outreach. 2018. https://doi. org/10.1186/s12052-018-0077-7.

Prentiss AM, Skelton RR, Eldredge N, Quinn C. Get Rad! the Evolution of the Skateboard Deck. Evol Edu Outreach. 2011;4(3):379-89. https://doi. org/10.1007/s12052-011-0347-0.

Pugh KJ. Transformative experience: An integrative construct in the spirit of Deweyan Pragmatism. Edu Psychol. 2011;46(2):107-21. https://doi. org/10.1080/00461520.2011.558817.

Pugh KJ, Koskey KLK, Linnenbrink-Garcia L. High school biology students' transfer of the concept of natural selection: a mixed-methods approach. J Biol Edu. 2014;48(1):23-33. https://doi.org/10.1080/00219 266.2013.801873.

Pugh KJ, Linnenbrink-Garcia L, Koskey KLK, Stewart VC, Manzey C. Motivation, learning, and transformative experience: A study of deep engagement in science. Sci Edu. 2010;94(1):1-28. https://doi.org/10.1002/sce.20344.

Rice SH. Evolutionary theory: mathematical and conceptual foundations. Sinauer Associates. 2004

Richerson PJ, Boyd RT. Not by Genes Alone. How Culture Transformed Human Evolution. Chicago, USA: University of Chicago Press; 2005.

Rosenbaum DA. It's a Jungle in There: How Competition and Cooperation in the Brain Shape the Mind. Oxford University Press. 2014

Rosengren K, Brem SK, Evans EM, Sinatra GM. Evolution challenges: integrating research and practice in teaching and learning about evolution. Oxford: Oxford University Press; 2012. https://doi.org/10.1093/acprof:oso/97801 99730421.001.0001.

Shtulman A. Qualitative differences between naïve and scientific theories of evolution. Cogn Psychol. 2006;52(2):170-94. https://doi.org/10.1016/j. cogpsych.2005.10.001.

Shtulman A. Scienceblind: Why our intuitive theories about the world are so often wrong. Hachette UK. 2017

Shtulman A, Neal C, Lindquist G. Children's ability to learn evolutionary explanations for biological adaptation. Early Edu Develop. 2016;27(8):122236. https://doi.org/10.1080/10409289.2016.1154418.

Shtulman A, Schulz L. The relation between essentialist beliefs and evolutionary reasoning. Cogn Sci. 2008;32(6):1049-62. https://doi. org/10.1080/03640210801897864. 
Sinatra GM. The "Warming Trend" in Conceptual Change Research: The Legacy of Paul R. Pintrich Edu Psychol. 2005;40(2):107-15. https://doi. org/10.1207/s15326985ep4002.

Sinatra GM, Brem SK, Evans EM. Changing minds? implications of conceptual change for teaching and learning about biological evolution. Evol Edu Outreach. 2008;1 (2):189-95. https://doi.org/10.1007/s1205 2-008-0037-8.

Smith JM, Szathmáry E. The Major Transitions in Evolution. New York: Oxford University Press; 1995.

Stern J, Ferraro K, Mohnkern J. Tools for teaching conceptual understanding Secondary. Corwin: Designing Lessons Assessments Deep Learning; 2017

Sweller J, Sweller S. Natural information processing systems. Evolu Psychol. 2006;4:434-58. https://doi.org/10.1177/147470490600400135.

Thanukos A. Coevolution in the Classroom. Evol Edu Outreach. 2010;3(1):71-7. https://doi.org/10.1007/s12052-009-0203-7.

Thompson JN. Four central points about coevolution. Evolution Edu Outreach. 2010. https://doi.org/10.1007/s12052-009-0200-x.

Tomasello M. Why we cooperate. Cambridge: MIT Press; 2009.

University of California Museum of Paleontology. (2009). Understanding Evolution conceptual framework. Berkeley, California, USA. Retrieved from http://evolution.berkeley.edu/evolibrary/teach/ue_framework.pdf

van Dijk EM, Reydon TAC. A conceptual analysis of evolutionary theory for teacher education. Sci Edu. 2010;19(6-8):655-77. https://doi. org/10.1007/s11191-009-9190-x.

Varella MAC. The biology and evolution of the three psychological tendencies to anthropomorphize biology and evolution. Front Psychol. 2018. https ://doi.org/10.3389/fpsyg.2018.01839.

Vendetti MS, Matlen BJ, Richland LE, Bunge SA. Analogical reasoning in the classroom: insights from cognitive science. Mind Brain Edu. 2015;9(2):100-6. https://doi.org/10.1111/mbe.12080.

Venville G, Gribble SJ, Donovan J. An exploration of young children's understandings of genetics concepts from ontological and epistemological perspectives. Sci Edu. 2005;89(4):614-33. https://doi.org/10.1002/ sce. 20061.
Werth A. Clearing the highest hurdle: Human-based case studies broaden students' knowledge of core evolutionary concepts. J Effective Teaching. 2009;9(2):38-58.

Whiten A, van Schaik CP. The evolution of animal "cultures" and social intelligence. Philos Trans R Soc B Biol Sci. 2007;362(1480):603-20. https://doi. org/10.1098/rstb.2006.1998.

Wilensky U. NetLogo Ethnocentrism model. 2003. http://ccl.northwestern.edu/ netlogo/models/Ethnocentrism. Center for Connected Learning and Computer-Based Modeling, Northwestern University, Evanston, IL

Wilson DS. Evolution for everyone: how to increase acceptance of, interest in, and knowledge about evolution. PLoS Biology. 2005;3(12):2058-65. https://doi.org/10.1371/journal.pbio.0030364.

Wilson DS. Does Altruism exist? culture, genes, and the welfare of others. New Haven: Yale University Press; 2015.

Wilson DS, Geher G, Gallup AG, Head H. (Eds.), Darwin's roadmap to the curriculum: evolutionary studies in higher education. New York, Oxford University Press.

Xu D, Chi MTH. Bridging emergent attributes and darwinian principles in teaching natural selection. Universal J Edu Res. 2016. https://doi. org/10.13189/ujer.2016.040522.

Zeder MA. Domestication as a model system for niche construction theory. Evol Ecol. 2016;30(2):325-48. https://doi.org/10.1007/s1068 2-015-9801-8

Ziadie MA, Andrews TC. Moving evolution education forward: a systematic analysis of literature to identify gaps in collective knowledge for teaching. CBE Life Sciences Education. 2018. https://doi.org/10.1187/ cbe.17-08-0190.

\section{Publisher's Note}

Springer Nature remains neutral with regard to jurisdictional claims in published maps and institutional affiliations.
Ready to submit your research? Choose BMC and benefit from:

- fast, convenient online submission

- thorough peer review by experienced researchers in your field

- rapid publication on acceptance

- support for research data, including large and complex data types

- gold Open Access which fosters wider collaboration and increased citations

- maximum visibility for your research: over 100M website views per year

At BMC, research is always in progress.

Learn more biomedcentral.com/submissions 